\title{
The Cellular and Synaptic Location of Activated TrkB in Mouse Hippocampus During Limbic Epileptogenesis
}

\author{
Jeffrey Helgager ${ }^{1}$, Gumei Liu' ${ }^{1}$, and James O. McNamara1,2,3 \\ ${ }^{1}$ Department of Neurobiology, Duke University Medical Center, Durham, NC, 27710, USA \\ ${ }^{2}$ Department of Medicine (Neurology), Duke University Medical Center, Durham, NC, 27710, USA \\ ${ }^{3}$ Department of Pharmacology and Molecular Cancer Biology, Duke University Medical Center, \\ Durham, NC, 27710, USA
}

\begin{abstract}
Understanding the mechanisms of limbic epileptogenesis in cellular and molecular terms may provide novel therapeutic targets for its prevention. The neurotrophin receptor, tropomyosinrelated kinase B (TrkB), is thought to be critical for limbic epileptogenesis. Enhanced activation of TrkB, revealed by immunodetection of enhanced phosphorylated TrkB (pTrkB), a surrogate measure of its activation, has been identified within hippocampus in multiple animal models. Knowledge of the cellular locale of activated TrkB is necessary to elucidate its functional consequences. Using an antibody selective to pTrkB in conjunction with confocal microscopy and cellular markers, we determined the cellular and subcellular locale of enhanced pTrkB induced by status epilepticus (SE) evoked by infusion of kainic acid into the amygdala of adult mice. SE induced enhanced pTrkB immunoreactivity in two distinct populations of principal neurons within hippocampus, the dentate granule cells and CA1 pyramidal cells. Enhanced immunoreactivity within granule cells was found within mossy fiber axons and giant synaptic boutons. By contrast, enhanced immunoreactivity was found within apical dendritic shafts and spines of CA1 pyramidal cells. A common feature of this enhanced pTrkB at these cellular locales is its localization to excitatory synapses between excitatory neurons, presynaptically in the granule cells and postsynaptically in CA1 pyramidal cells. Long term potentiation (LTP) is one cellular consequence of TrkB activation at these excitatory synapses that may promote epileptogenesis.
\end{abstract}

\section{Keywords}

neurotrophin; TrkB; epilepsy; seizures; hippocampus

\section{INTRODUCTION}

Epilepsy is a serious common neurological disorder, afflicting an estimated $1 \%$ of the population worldwide. Limbic epilepsy (synonymous with temporal lobe epilepsy [TLE]) is particularly problematic because it is both common and commonly resistant to optimal

\footnotetext{
(C) 2012 Wiley Periodicals, Inc.

Corresponding author: James O. McNamara, M.D., Phone: 919-684-4241, jmc@ neuro.duke.edu. CONFLICT OF INTEREST STATEMENT

The authors state no conflict of interest.

Red-green figures have been reproduced as magenta-green supplementary figures as follows: Figure 3 is Supplementary Figure 1. Figure 4 is Supplementary Figure 2. Figure 5A-F is reproduced as Supplementary Figure 3. Figure 7 is Supplementary Figure 4. Figure 9A-I is reproduced as Supplementary Figure 5.
} 
contemporary treatment (Arroyo et al., 2002). Clinical observations led Sir William Gowers (1881) to propose that seizures themselves promote progression of epilepsy, a proposal supported by subsequent studies of animal models in which recurrent seizures alone are sufficient to destroy limbic neurons and induce lifelong severe epilepsy (Sayin et al., 2003). An extension of Gowers' hypothesis is that an episode of continuous seizure activity spanning 30 minutes to hours (status epilepticus, SE) is sufficient to induce TLE that persists for a lifetime. Indeed SE alone is sufficient to induce TLE in models of both developing and adult rodents (Dunleavy et al., 2010; Loscher, 2002). Circumstantial evidence supports the idea that SE contributes to the pathogenesis of TLE in humans (Annegers et al., 1979; Tsai et al., 2009; VanLandingham et al., 1998).

Understanding how seizures promote induction and/or progression of epilepsy may reveal molecular targets for preventive therapy. Experimental evidence suggests that the neurotrophin, brain-derived neurotrophic factor (BDNF), promotes limbic epileptogenesis by activation of its cognate receptor, tropomyosin-related kinase B (TrkB). Epileptogenesis was markedly impaired in the kindling model in mice heterozygous for the BDNF gene or in rats following intraventricular infusion of a BDNF scavenging protein (Binder et al., 1999b; Kokaia et al., 1995). Conditional deletion of TrkB in mice abolished limbic epileptogenesis in an animal model induced by recurrent seizures (He et al., 2004), demonstrating that TrkB is necessary for limbic epileptogenesis. Transgenic overexpression of BDNF enhances limbic epileptogenesis (Croll et al., 1999), as does direct infusion of BDNF into hippocampus of adult rodents (Xu et al., 2004), suggesting that excess activation of TrkB by BDNF is sufficient to promote limbic epilepsy. Importantly, diverse models of limbic epileptogenesis exhibit enhanced activation of TrkB (Binder et al., 1999a; Danzer et al., 2004; He et al., 2004; He et al., 2002; He et al., 2010) as evidenced by a surrogate measure, namely increased tyrosine phosphorylation (Segal et al., 1996). Collectively, these findings underscore the importance of elucidating the cellular consequences of enhanced TrkB activation because these are likely to promote limbic epileptogenesis.

Establishing the cellular and subcellular locale of the enhanced TrkB activation evident during limbic epileptogenesis is necessary to elucidate its cellular consequences. Using an antibody that recognizes the phosphorylated tyrosine 816 (pY816) of TrkB together with cellular markers and confocal microscopy, we examined the anatomic locale of pY816 TrkB immunoreactivity in a model of limbic epileptogenesis involving SE induced by microinfusion of the chemoconvulsant kainic acid (KA) into the basolateral amygdala of adult mice (Araki et al., 2002; Li et al., 2008; Mouri et al., 2008). Advantages of this model include low mortality, as well as the reliable induction of spontaneous recurrent seizures and hippocampal pathology similar to humans with TLE (Mathern et al., 1997). Notably, work employing mice with mutations in either of two key TrkB tyrosine signaling residues, Y816 and Y515, revealed that Y816, but not Y515, is critical for the development of epilepsy (He et al., 2002; He et al., 2010), underscoring the rationale for examining the phosphorylation of this particular tyrosine residue of TrkB during epileptogenesis. The present studies reveal evidence of enhanced TrkB activation in two populations of neurons within hippocampal circuitry - dentate granule cells and CA1 pyramidal cells. The enhanced TrkB activation was localized in part to excitatory synapses in each of these neuronal populations.

\section{MATERIALS AND METHODS}

\section{Thy1 GFP-expressing mice}

C57/BL6 mice which express a green fluorescent protein (GFP) transgene under control of the Thy 1 promoter were a generous gift from Dr. Guoping Feng. These mice were of either the $\mathrm{M}$ or $\mathrm{O}$ line, as described previously (Feng et al., 2000). Animals used for experiments were bred from mice hemizygous for the Thy1 GFP allele crossed to wild type C57/BL6 
mice from a local colony, the founders of which were originally obtained from Charles River (Wilmington, MA). Thy1 GFP animals were crossed to the local colony for at least five generations before use in experimentation. Thy 1 belongs to the Ig superfamily and is expressed in both neuronal as well as non-neuronal cells, and both lines express GFP in a subset of dentate granule cells, as well as CA3 and CA1 pyramidal cells. Importantly for the purpose of this study, these cells represent typical granule and pyramidal cells in that their dendritic, axonal, and somatic morphologies reflect patterns observed using other techniques (Ramón y Cajal, 1911). Dentate granule cell mossy fiber axons expressing GFP can be visualized, and their giant boutons are easily identifiable based on their location within stratum lucidum, their continuity with the axon, and their large size $\left(8-17 \mu \mathrm{m}^{2}\right)$ (Amaral and Dent, 1981). The dendritic processes and spines of GFP-expressing pyramidal neurons within hippocampus, though more sparse, are also readily observable. These mice have been used previously as a means of examining the cellular morphology of hippocampal neurons, as well as for colocalization analyses similar to those performed in this study (Copanaki et al., 2010; Danzer et al., 2008; Danzer and McNamara, 2004; Walter et al., 2007).

\section{Induction of SE}

All animal procedures described were approved for use by the Institutional Animal Care and Use Committee (IACUC) at Duke University, and conformed to National Institutes of Health and Duke University institutional guidelines for the care and use of animals. Animals were maintained on 12 hour light/dark cycles. Littermate GFP-expressing and nonexpressing mice were included in experiments, and an effort was made to pair control and SE treated animals of the same GFP genotype whenever possible. Mice that died during treatment or that did not develop SE were discarded from the experiment.

SE Induced by Microinfusion of KA-A model of limbic epileptogenesis whereby SE was induced by microinfusion of KA into the basolateral amygdala was adopted for the majority of experiments conducted in this study, and has been extensively characterized in C57/BL6 mice (Araki et al., 2002; Li et al., 2008; Mouri et al., 2008). This model was selected for several reasons: a) animals usually develop SE; b) animals undergoing SE uniformly develop spontaneous recurrent seizures after a seizure free latent period of 3-6 days; c) mortality is low; d) unlike systemic administration of KA in C57/BL6 mice (Schauwecker and Steward, 1997), hippocampal sclerosis similar to that of human TLE develops in the hippocampus ipsilateral to the amygdala into which KA is infused. The unilaterality of the hippocampal damage also provides the advantage of an intra-animal control not present in other models.

It should be noted, however, that prominent cell death is not found directly following SE induced by KA microinfusion into amygdala in C57/BL6 mice (Kasugai et al., 2007), such as at the time point examined in this study, but rather occurs over subsequent days and weeks (Araki et al., 2002; Li et al., 2008; Mouri et al., 2008). In the present study, pY816 immunoreactivity was examined under conditions where cell damage should be minimal, as the presence of significant amounts of dead tissue would have confounded the ability to accurately quantify pY816 immunoreactivity in the remaining viable neuropil. This was exemplified in two KA treated animals in this study that were found to have disruption of the cytoarchitecture within stratum lucidum accompanied by a loss of pY816 staining, and were subsequently discarded from analysis (see below). The paucity of cell death in this study is reinforced by the presence of GFP+ pyramidal cells and their processes in KA treated Thy1 GFP mice; no obvious differences in their numbers or morphology were evident in NS compared to KA infused animals. 
A total of 34 mice undergoing infusion of KA or NS into the right amygdala were used in this portion of the study. Both male and female C57BL/6 mice aged 3-6 months old and weighing at least $20 \mathrm{~g}$ were anesthetized with $60 \mathrm{mg} / \mathrm{kg}$ pentobarbital (Lundbeck, Deerfield, IL) via intraperitoneal injection and placed in a stereotactic frame. Animals were surgically implanted with a guide cannula (1.1 $\mathrm{mm}$ posterior, $2.9 \mathrm{~mm}$ lateral to Bregma; Plastics One, Roanoke, VA), following which a bipolar electrode was inserted into the contralateral dorsal hippocampus ( $2.0 \mathrm{~mm}$ posterior, $1.6 \mathrm{~mm}$ lateral to Bregma, depth of $1.5 \mathrm{~mm}$ below dura). Mice were allowed to recover postoperatively for at least three days. Before microinfusions, digital EEG recording commenced from the previously placed hippocampal electrode (Grass Technologies, West Warwick, RI). An injection cannula (Plastics One) was inserted through the guide cannula at a depth of $4.6 \mathrm{~mm}$ below dura so as to target basolateral amygdala. Through this cannula, a total of 21 mice to be given SE received infusions of $0.3 \mu \mathrm{g}$ of KA (Sigma, St. Louis, MO) in $0.5 \mu \mathrm{L}$ of normal saline (NS) which was infused over a period of five minutes using a motorized infusion/withdrawal pump (Harvard Apparatus, Holliston, MA). A total of 13 mice to be used as surgical controls were infused with an equivalent volume of vehicle, NS, in the same fashion. The EEG was subsequently monitored for electrographic seizure activity, and mice were simultaneously observed for the development of behavioral SE. SE was defined as in (Danzer and McNamara, 2004): partial or whole body clonus, myoclonic jerks, rearing and falling, shivering, and/or loss of posture that was uninterrupted by normal behavior. Animals that developed SE were monitored until three hours after the first recorded electrographic seizure, at which time they were sacrificed, as described below, along with littermates that had been treated as surgical controls. Of the 21 animals infused with KA, four did not survive for the full three hours of SE, whereas another three failed to developed SE.

SE Induced by Pilocarpine-A total of 15 male and female C57/BL6 mice 2-3 months of age, generated as described above, were used in this portion of the study. Mice received methylscopolomine nitrate (1 mg/kg by intraperitoneal injection) (Sigma), in order to block peripheral effects of the subsequent pilocarpine treatment. Fifteen minutes later, animals to be given SE were injected with pilocarpine (375 mg/kg, intraperitoneal) (Sigma), whereas those to be used as controls were injected with NS. In total, 11 mice received pilocarpine treatment and four NS. Pilocarpine treated mice were observed for the development of behavioral SE as described above. An additional dose of pilocarpine $(75 \mathrm{mg} / \mathrm{kg}$, intraperitoneal) was administered to animals that failed to develop SE by 50 minutes following the initial pilocarpine injection. Animals were allowed to remain in SE for three hours at which time diazepam (10 mg/kg, intraperitoneal) (Hospira, Lake Forest, IL) was given to terminate seizure activity. Control animals also received diazepam. Animals were sacrificed, along with NS treated controls, at six hours following onset of SE. Of the 11 animals injected with pilocarpine, four did not survive the full SE episode and two failed to develop SE.

\section{Preparation of Brain Specimens for Immunohistochemistry}

Animals treated as above were anesthesized with $100 \mathrm{mg} / \mathrm{kg}$ pentobarbital by intraperitoneal injection and underwent transcardial perfusion through the left ventricle with a solution of ice-cold PBS, pH 7.4, containing $1 \mathrm{U} / \mathrm{mL}$ heparin (Sigma) and $2 \mathrm{mM}$ sodium orthovanadate (Sigma), at a rate of $10 \mathrm{ml} / \mathrm{min}$ for one minute. This was followed by a seven minute perfusion with ice-cold $4 \%$ paraformaldehyde (Sigma) and $2 \mathrm{mM}$ sodium orthovanadate in PBS, pH 7.4. Brains were removed and postfixed overnight at $4{ }^{\circ} \mathrm{C}$ in the same solution, after which they underwent cryoprotection for 36 hours in a solution of $30 \%$ sucrose, $2 \mathrm{mM}$ sodium orthovanadate in PBS at $\mathrm{pH} 7.4$ and $4^{\circ} \mathrm{C}$. Brains were verified as being appropriately cryoprotected when they sank in this solution. Brains were then frozen by slow immersion in 2-methylbutane (J.T. Baker, Phillipsburg, NJ) cooled to $-20^{\circ} \mathrm{C}$ with dry ice, and stored at 
$-80^{\circ} \mathrm{C}$ until cryosectioning. Sections were cut at a thickness of $40 \mu \mathrm{m}$, placed in cryoprotection solution, and stored at $-80^{\circ} \mathrm{C}$ until immunostaining. In animals that received KA microinfusions to induce SE, sections containing the cannula tract were examined to confirm that microinfusion had targeted the basolateral amygdala.

Any brains with misplaced cannulas or that were found to contain blood in the hippocampi upon sectioning, indicating a suboptimal perfusion, were discarded from further processing. Furthermore, sections from two animals treated with SE by KA microinfusion revealed disruption of the cytoarchitecture within stratum lucidum compared to control animals as determined by Nissl stain, probably a result of particularly severe SE (Fig. 2E, F; arrows). For this reason, these animals were discarded from the final quantitative analysis. The region of disrupted cytoarchitecture revealed striking paucity of pY816 staining compared to control mice (Fig. 2G, H; arrows), however it should be noted that inclusion of these animals would not have altered the statistical significance level of any results of this study.

\section{Antibody Characterization}

Details of antibodies employed in this study are provided in Table 1 (Primary Antibodies) and Table 2 (Secondary Antibodies). These antibodies were characterized in terms of their specificity as follows:

Rabbit polyclonal antibody which recognizes phosphorylated tyrosine residue 816 of the TrkB receptor (pY816) was generated using the peptide LQNLAKASPVpYLDI, corresponding to amino acids $806-819$ of mouse TrkB, and was used in all experiments at a 1:2000 dilution following IgG purification using protein-A beads. Importantly, the specificity of this antibody was previously established for immunohistochemistry (He et al., 2010). This was evidenced by demonstrating a significant reduction in immunoreactivity in stratum lucidum of genetically modified mice with a substitution of phenylalanine for tyrosine at the 816 residue (Y816F) of TrkB compared to wild type controls, as shown in Supplementary Figure 1 of (He et al., 2010).

A mouse monoclonal antibody recognizing GFP (1:1000; Millipore, Temecula, CA) was found to augment GFP fluorescence. This was tested by incubating GFP-expressing mouse brain sections with this antibody, followed by an Alexa Fluor-555 conjugated secondary antibody, which fluoresces red. Augmented (red) and endogenous (green) GFP fluorescence could be seen to overlap when viewed using an epifluorescent microscope. Mouse monoclonal MAP2 (1:500; Sigma), and Tau (1:1000; Millipore) antibodies were employed as tissue markers of dendrites and axons, respectively (Binder et al., 1985; Huber and Matus, 1984). MAP2 antibody was found to label what appeared to be dendrites throughout mouse brain, confirmed by the fact that dendritic shafts of GFP+ CA1 and CA3 pyramidal cells were found to colocalize with MAP2 immunoreactivity within CA3 stratum lucidum and CA1 stratum radiatum when examined in Thy 1 GFP mice. Tau immunoreactivity was found to colocalize with GFP+ mossy fiber axons in stratum lucidum, and was also excluded from $\mathrm{GFP}+$ dendrites that could be identified within this structure.

\section{Immunohistochemistry}

NS and SE treated littermates were always incubated in parallel using the same solutions and conditions. All incubations took place at $4{ }^{\circ} \mathrm{C}$ in $5 \%$ normal goat serum (Invitrogen) in PBS, pH 7.4, with $2 \mathrm{mM}$ sodium orthovanadate. Floating sections were permeabilized for one hour in $0.5 \%$ Triton-X100 (GE Healthcare, Chalfont St. Giles, UK), and solutions of primary antibodies added for 36 hours. Alexa Fluor 555 conjugated goat anti-rabbit (1:1000; Invitrogen) and, for colocalization experiments, Alexa Fluor 488 or 633 conjugated goat anti-mouse secondary antibodies (1:500; Invitrogen) were then applied for six hours. 
Adjacent sections not treated with primary antibody were also run in parallel for each animal as negative controls. Sections were wet-mounted on Superfrost Plus slides (Erie Scientific, Portsmouth, $\mathrm{NH}$ ) and stepped through serial dehydration solutions of two minutes each of $50 \%, 70 \%, 85 \%, 95 \%, 100 \%$, and $100 \%$ ethanol, followed by 20 minutes incubation in xylene (VWR, Radnor, PA) before coverslipping.

\section{Confocal Microscopy and Data Analysis}

Imaging Parameters-Imaging was performed with a Leica (Nussloch, Germany) DMIRE2 inverted microscope with a $10 \times$ (numerical aperture, 0.4 ) air or $63 \times$ (numerical aperture, 1.4) oil immersion objective equipped with a Leica TCS SL confocal system. All images were acquired with the pinhole set to 1.0 Airy units. All images shown for visual comparison between treatment groups or used for quantitative analysis were acquired so as to prevent systematic differences in image intensities between NS and SE animals. Specifically, sections obtained from control and SE treated littermates were incubated together within a given staining experiment and were imaged using the same laser intensity and detection settings during the same imaging session, thereby permitting relative densitometry measurements to be made between treatment groups. Because overall staining intensities necessarily varied between staining experiments, confocal settings were adjusted optimally for each experiment so that all image intensities fell within the dynamic range of detection of the device.

Low power (10× objective, total of $100 \times$ magnification) images of hippocampus are average projections of $z$-series "stacks" taken through the entire thickness of the hippocampal section. Unless otherwise stated, high power (63× objective, total of $630 \times$ magnification) images are average projections of $z$-series taken through a $1 \mu \mathrm{m}$ depth of hippocampus where pY816 staining was of greatest intensity. Average projections were used because they best reflect representative staining intensities in the $z$-plane for quantification of immunoreactivity. Images depicting colocalizations were confirmed in the $x, y$, and $z$ dimensions. The focal plane thickness is a significant factor in the $z$-dimension. For the $63 \times$ objective used in this study, assuming ideal conditions and $488 \mathrm{~nm}$ of light, $z$ resolution is stated to be $235 \mathrm{~nm}$ (Leica). The resolution in the $x-y$ plane is stated to be $180 \mathrm{~nm}$ (Leica). All image quantification described was performed on raw images which were not adjusted for brightness or contrast. However, brightness and/or contrast were optimized in all images shown within this manuscript in order to best convey relevant features. In images of pY816 immunoreactivity used for comparison, brightness and contrast were adjusted equally between images.

Quantification of pY816 Immunoreactivity-Analysis of imaging data was performed by an investigator blinded to treatment group. The program ImageJ (Abramoff, 2004) was used for data analysis. All quantitative data is presented as mean \pm SEM, analyzed by 1-way ANOVA with significance values between individual groups determined by post-hoc Bonferroni's test.

For quantification of stratum lucidum immunoreactivity for animals in the KA model of SE, one hippocampal image including the $\mathrm{CA} 3 \mathrm{~b}$ regions of stratum lucidum and stratum radiatum, taken both ipsilateral and contralateral to the side of infusion, was used from each animal acquired at both low power $(100 x)$ and high power (630x). If there was any discrepancy in stratum lucidum brightness between sections, that with the brightest stratum lucidum immunoreactivity was used. Low power quantification of pY816 immunoreactivity within stratum lucidum was performed by outlining a square region of interest (ROI) in the $\mathrm{CA} 3 \mathrm{~b}$ region, of uniform dimension for all images sampled, and taking the average intensity within this region. The average intensity of an ROI of equal dimension was taken within 
stratum radiatum of CA3, reflective of background immunoreactivity, and subtracted from the stratum lucidum value so as to compensate for differences in background staining intensity between animals. Other hippocampal regions quantified at low power $(100 \times)$ were analyzed in the same fashion. Quantification at high power (630x) focused on specific areas within stratum lucidum that were enhanced in pY816 immunoreactivity and shown to correspond to axon tracts in colocalization experiments. Representative regions enriched in pY816 immunoreactivity were outlined as ROIs until 50,000 pixels in total area were reached or exceeded, and the average intensity of this area quantified. The average intensity of stratum radiatum of CA3 that was included in the same micrograph was also taken, and subtracted from the value obtained from stratum lucidum in order to compensate for variations in background staining. Signal within stratum radiatum was used for normalization for several reasons: a) signal within stratum radiatum immunoreactivity was always substantially lower than stratum lucidum; b) signal within stratum radiatum was found to be of the same average intensity when compared between control and SE treated animals at both low power (100x) and high power (630x) (data not shown); c) the CA3 pyramidal cell dendrites which populate this region were found not to contain significant amounts of pY816 immunoreactivity (Fig. 6E; CA3 SR; also observe CA3 stratum radiatum in Fig. 2A-D).

For quantification of other regions within hippocampus, the investigator counted the total numbers of individual neuronal processes discerned within a given region within an image. In mice treated with the KA microinfusion model, two images were taken both ipsilateral and contralateral to the site of infusion in each of the following regions for every animal: CA1 stratum radiatum, CA1 stratum oriens, CA1 stratum lacunosum moleculare, CA3 stratum radiatum, CA3 stratum oriens, and the suprapyramidal and infrapyramidal molecular layers of dentate gyrus. In mice treated with the pilocarpine model, two images from each side were taken from each of the regions above, and those that appeared to display the greatest number of neuronal processes were used for analysis. In order to quantify how far within apical dendritic shafts of CA1 pyramidal cells the pY816 immunoreactivity extended into stratum radiatum, individual GFP+ apical shafts that could be traced through the vertical extent of stratum radiatum were imaged in a KA infused animal in the hippocampus ipsilateral to microinfusion. In those dendritic shafts that contained pY816 immunoreactivity, measurements were made of both the distance from the soma that this immunoreactivity was observed, and the total dendritic length within stratum radiatum of CA1. From these measurements, the percent of the total length of the dendritic shaft containing pY816 immunoreactivity was calculated.

Quantification of synaptic pY816 immunoreactivity employed just the subset of mice that expressed Thy 1 GFP (5 KA and 5 NS out of 9 KA and 9 NS). Sections from these animals treated in the KA microinfusion model were imaged within a given region both ipsilateral and contralateral to the side of infusion. For quantification of pY816 immunoreactivity within giant mossy fiber boutons of stratum lucidum, $z$-series were acquired at $200 \mathrm{~nm}$ intervals over a total depth of $1 \mu \mathrm{m}$. For quantification of immunoreactivity within dendritic spines of stratum radiatum of CA1, stratum oriens of CA1, stratum lacunosum moleculare of $\mathrm{CA} 1$, stratum radiatum of $\mathrm{CA} 3$, and the outer two thirds of the suprapyramidal and infrapyramidal molecular layers, $z$-series were taken at $250 \mathrm{~nm}$ intervals over a total depth of $2 \mu \mathrm{m}$. Note that pY816 antibody generally penetrated sections only superficially, but this was particularly pronounced within stratum lucidum, limiting the depth in which immunoreactivity could be imaged in this region more than the others. Individual spines and boutons from each of these regions were checked for pY816 immunoreactivity in the $x, y$, and $z$ planes, and scored as being positive if they appeared to contain at least one discrete immunoreactive puncta, even if only in one $z$-section. This immunoreactivity needed to 
occupy at least $20 \%$ of the area of a bouton, whereas for a spine the majority of its area needed to be filled.

\section{RESULTS}

\section{Enhanced pY816 immunoreactivity within stratum lucidum following kainic acid status epilepticus (KA-SE)}

Initial studies centered on characterization of the intensity of pY816 immunoreactivity within stratum lucidum in the KA model. As KA microinfusion directly activates limbic structures on the side in which it is infused (Araki et al., 2002), pY816 immunoreactivity was examined in stratum lucidum both ipsilateral and contralateral to the side of infusion. Littermate mice were infused with either normal saline (NS) or KA, and those receiving the latter treatment allowed to seize for three hours following the first electrographic seizure, as recorded from a bipolar electrode in CA1 of the hippocampus contralateral to the side of infusion. At this time mice were sacrificed along with their NS controls and coronal sections containing dorsal hippocampi were stained with pY816 antibody. Visual inspection at low magnification (100x) revealed striking increases of pY816 immunoreactivity in stratum lucidum ipsilateral to KA microinfusion compared to contralateral stratum lucidum or to NS treated mice (Fig. 1AD; compare panel D to others, arrows point to stratum lucidum). Quantification of pY816 immunoreactivity within CA3b of stratum lucidum using low power (100x) images revealed approximately a 2 -fold increase ipsilateral to KA infusion $(n=9)$ compared to NS littermates ( $n=9)$ (Fig. 1E; CA3 SL; $p<0.001$ ); by contrast, only a 1.3-fold increase was observed contralateral to KA infusion ( $p>0.05$ ). Thus, pY816 immunoreactivity was preferentially increased within stratum lucidum ipsilateral to the KA infused amygdala, a site at which immunoreactivity in all KA treated mice $(\mathrm{n}=9)$ exceeded that of either side in NS treated littermates. Furthermore, in all but one KA treated animal $(n=8), p Y 816$ immunoreactivity was greater ipsilaterally than contralaterally. Except for stratum radiatum of CA1 (see below), no overt changes in pY816 TrkB immunoreactivity were evident in other regions of hippocampus following KA-SE, consistent with past reports (Binder et al., 1999a; Danzer et al., 2004; He et al., 2004; He et al., 2002; He et al., 2010); quantification within stratum oriens and stratum lacunosum moleculare of CA1 revealed no significant differences in immunoreactivity between NS $(n=9)$ and KA $(n=9)$ infused animals (Fig. 1E; CA1 SO and CA1 SLM).

Stratum lucidum was also visualized at high magnification (630x) in sections from the same NS $(n=9)$ and KA $(n=9)$ treated mice as above (Fig. 2A-D). This revealed discrete patches of pY816 immunoreactivity within CA3b of stratum lucidum, which appeared noticeably brighter in hippocampi ipsilateral to infusion in KA treated animals (Fig. 2A-D; compare panel D to others, arrows mark areas of enhanced immunoreactivity), confirming observations at low magnification (100x). Importantly, the pattern of pY816 immunoreactivity was similar in NS and KA treated animals, suggesting that the cellular locale was similar in experimental and control conditions.

\section{Localization of stratum lucidum pY816 immunoreactivity to mossy fiber axons}

To further explore the cellular and subcellular locations of the discrete patches of pY816 TrkB immunoreactivity in stratum lucidum observed at high magnification (630X), sections from NS and KA infused animals examined above were co-labeled with pY816 antibody and various markers of cellular structures, and confocal microscopy used to examine colocalization. To survey pY816 immunoreactivity within mossy fiber axons and giant boutons, a transgenic mouse that expresses green fluorescent protein (GFP) under control of the Thy1 promoter was employed for a subset of the KA microinfusion experiments (Feng et al., 2000). Subsets of dentate granule cells are labeled with GFP in these mice, and GFP fills 
the processes of these cells so that mossy fiber axons and their giant boutons can be directly visualized (Danzer et al., 2008; Danzer and McNamara, 2004). pY816 immunoreactivity prominently colocalized with GFP-labeled mossy fiber axons in CA3b of stratum lucidum in both NS (n=5) and KA (n=5) mice (Fig. 3A-I and Supplementary Fig. 1A-I; arrows). This immunoreactivity was finely granular but appeared relatively homogeneous throughout the axons. A subset of giant boutons of mossy fiber axons exhibited pY816 immunoreactivity in both NS and KA treated animals (see below), though most did not contain prominent immunoreactivity (Fig. 3D-I and Supplementary Fig. 1D-I; arrows with asterisks).

Though GFP-expressing mice permit visualization of fine structures of dentate granule cells, only a subset of mossy fiber axons are labeled with GFP, and therefore the full extent of pY816 overlap with mossy fiber axons could not be appreciated. To circumvent this limitation, axons were visualized with an antibody to the protein tau, which selectively labels axons (Binder et al., 1985). Striking overlap of tau and pY816 immunoreactivity in the $\mathrm{CA} 3 \mathrm{~b}$ region of stratum lucidum was evident in a control mouse (Fig. $3 \mathrm{~J}-\mathrm{L}$ and Supplementary Fig. 1J-L; arrows), further supporting axonal localization of pY816. Difficulties in detecting tau immunoreactivity following SE precluded its study in KA treated animals.

To determine whether pY816 immunoreactivity is detectable within dendrites of CA3 pyramidal cells which populate stratum lucidum and onto which giant boutons of dentate granule cells form synapses, an antibody for MAP2 was employed. The MAP2 protein is selectively expressed in dendrites (Huber and Matus, 1984) which were oriented largely perpendicular in CA3b of stratum lucidum in coronal sections (Fig. 4B, E and Supplementary Fig. 2B, E; arrows with asterisks). In sharp contrast to axonal markers, no prominent overlap of pY816 and MAP2 immunoreactivity was detected in either NS (n=3) or KA $(n=3)$ treated animals (Fig. 4 and Supplementary Fig. 2). Collectively, these findings demonstrate that pY816 immunoreactivity is largely confined to mossy fiber axons and boutons under both basal conditions and following KA-SE, not within dendrites of CA3 pyramids.

Given the localization of pY816 immunoreactivity within stratum lucidum to axons of dentate granule cells, additional quantification of immunoreactivity within these structures was performed at high power $(630 \times)$ in the same NS $(n=9)$ and KA $(n=9)$ treated mice used for the low power $(100 \times)$ quantification (Fig. 2A-D shows representative $630 \times$ images). Unlike the low power $(100 \times)$ quantification performed above, this high power $(630 \times)$ quantification specifically measured immunoreactivity found within axon tracts of stratum lucidum (see Materials and Methods), thus focusing on the anatomical locale where pY816 immunoreactivity was most prominent. Quantification revealed a significant increase of pY816 immunoreactivity on the side ipsilateral to KA infusion of approximately 2-fold (NS $=51.5 \pm 8.4, \mathrm{KA}=105.1 \pm 8.1$, mean \pm SEM, intensity units); by contrast, an increase of 1.5 -fold was detected contralaterally $(\mathrm{NS}=53.9 \pm 8.1, \mathrm{KA}=78.9 \pm 7.9$, mean $\pm \mathrm{SEM}$, intensity units). As with the low power (100x) quantification, this difference was significant only on the side ipsilateral to KA infusion ( $\mathrm{p}<0.001$, one-way ANOVA; $\mathrm{p}<0.001$ ipsilateral NS vs. ipsilateral KA, $\mathrm{p}<0.001$ contralateral NS vs. ipsilateral KA, post-hoc Bonferroni's test). The high power $(630 \times)$ quantification mirrored the low power $(100 \times)$ in that immunoreactivity ipsilateral to infusion was greater than contralateral in KA infused mice in all but the one animal where this was not observed with low power (100x) quantification $(n=8)$; in all KA infused animals $(n=9)$, the pY816 immunoreactivity in stratum lucidum ipsilateral to KA infusion exceeded that on either side in NS infused littermates.

To determine whether this cellular and subcellular location of pY816 TrkB was generalizable to other models of epileptogenesis, additional mice underwent three hours of 
SE induced by systemically administered pilocarpine ( $\mathrm{n}=5)$, and were matched with NS injected littermate controls $(n=4)$. A subset of these animals contained the Thy1 GFP transgene. Like the KA microinfusion model, pY816 immunoreactivity exhibited striking colocalization with GFP-labeled mossy fiber axons but not with dendrites labeled with MAP2 following pilocarpine SE. A subset of giant boutons of mossy fiber axons exhibited pY816 immunoreactivity in both NS and pilocarpine SE treated animals (data not shown). Thus, pY816 immunoreactivity exhibits similar patterns of cellular localization following SE in two distinct models.

\section{Enhanced pY816 immunoreactivity within synaptic mossy fiber boutons following KA-SE}

A subset of GFP+ giant boutons of mossy fibers in stratum lucidum in Thy1 GFP mice exhibited pY816 immunoreactivity (Fig. 5A-F and Supplementary Fig. 3A-F; arrow demarks a pY816+ bouton, arrow with asterisk demarks a bouton not prominently immunoreactive). In contrast to the finely granular pattern of pY816 immunoreactivity within mossy fiber axons, the immunoreactivity within boutons was punctate in nature. To determine whether immunoreactivity within giant boutons increased during epileptogenesis, GFP+ boutons were imaged in the subset of mice treated with NS $(n=5)$ or KA-SE $(n=5)$ that expressed Thy 1 GFP. A stack of $z$-sections were scored for pY816 immunoreactivity by a blinded investigator; a bouton was deemed positive if it contained a discrete pY816 puncta that filled at least $20 \%$ of the bouton in at least one $z$-section. A total of over 1800 boutons were scored in this fashion.

Under basal conditions, a small fraction (average of 6.5\%) of GFP+ boutons in stratum lucidum exhibited pY816 immunoreactivity. Strikingly, the fraction of GFP+ boutons exhibiting pY816 immunoreactivity increased approximately 4-fold in the stratum lucidum ipsilateral to the amygdala infused with KA (Fig. 5G; NS $=5.4 \pm 2.0 \%, \mathrm{KA}=20.2 \pm 2.9 \%$, mean \pm SEM; $\mathrm{p}<0.05)$; a 1.9-fold increase was evident in stratum lucidum in the contralateral hippocampus (NS $=7.7 \pm 1.9 \%, \mathrm{KA}=14.7 \pm 3.0 \%$, mean $\pm \mathrm{SEM}$; $\mathrm{p}>0.05$ ). The increased fraction of pY816 immunoreactive synaptic boutons paralleled the increase of mossy fiber axonal immunoreactivity in that it was most prominent in the hippocampus ipsilateral to the KA infused amygdala. Towards this end, more boutons were labeled with pY816 in the stratum lucidum ipsilateral to KA infusion than on the contralateral side in all KA treated mice examined $(n=5)$. Furthermore, percentages of boutons labeled on the ipsilateral side in all KA treated mice $(n=5)$ were always greater than the percentages labeled in NS infused littermates on either side relative to infusion.

\section{Localization of pY816 immunoreactivity within apical dendritic shafts of CA1 pyramidal cells following KA-SE}

Although no significant increases in pY816 TrkB immunoreactivity were detected in low power (100x) analyses of stratum radiatum of CA1 following SE induced by KA microinfusion (Fig. 1F), high power (630x) analyses of sections from these same mice revealed increases within neuronal processes populating this region in KA treated animals $(\mathrm{n}=9)$ compared to those infused with NS ( $\mathrm{n}=9$ ) (Fig. 6A-D; arrows point to $\mathrm{pY} 816+$ dendritic shafts). The failure to detect an increased intensity of the CA1 stratum radiatum region in low power analyses following SE is due to the fact that only a subset of these processes exhibited increased immunoreactivity. This increased pY816 immunoreactivity was found to colocalize with a subset of GFP+ apical dendritic shafts of CA1 pyramidal cells (Fig. 7A-C and Supplementary Fig. 4A-C; arrows), identified as such based on the fact that they emanated from cell bodies in stratum pyramidale in the direction of stratum lacunosum moleculare (Ramón y Cajal, 1911). Like the pY816 immunoreactivity within stratum lucidum, pY816 immunoreactive apical dendritic shafts of CA1 pyramidal cells were most prominent in the hippocampus ipsilateral to the KA-infused amygdala (Fig. 6A- 
$\mathrm{D}$; compare panel $\mathrm{D}$ to others). Counting the number of pY816-immunoreactive processes detected in a total of two high power (630x) fields taken from stratum radiatum of CA1 (Fig. $6 \mathrm{E}$; CA1 SR) revealed a 3.6-fold increase on the side ipsilateral to KA microinfusion compared to NS controls ( $\mathrm{NS}=19.3 \pm 2.6, \mathrm{KA}=70.2 \pm 13.2$, mean $\pm \mathrm{SEM}$, number of pY816+ neuronal processes; $\mathrm{p}<0.01$ ); contralaterally, a 1.8-fold increase in number of pY816-immunoreactive processes was detected (NS $=20.0 \pm 5.3, \mathrm{KA}=36.2 \pm 12.5$, mean \pm SEM, number of pY816+ neuronal processes, $\mathrm{p}>0.05$ ). In all but one KA-SE treated animal $(n=8)$, more immunoreactive processes were observed on the side ipsilateral to infusion than on the contralateral side, or on either side in NS infused littermates. In the one KA infused animal where these observations did not hold, no dendritic processes were detected in stratum radiatum of CA1 on either side, despite a clear lateralized increase in pY816 immunoreactivity within stratum lucidum compared to NS infused littermates.

Localization of pY816 immunoreactivity to apical dendritic shafts of CA1 pyramidal cells in KA treated animals exhibited striking anatomic specificity. That is, basal dendritic shafts of CA1 pyramidal cells did not exhibit prominent pY816 immunoreactivity (Fig. 7A-C and Supplementary Fig. 4A-C; arrows with asterisks) nor were significant differences detected in stratum oriens of CA1 between NS $(n=9)$ and KA $(n=9)$ treated animals in the hippocampus either ipsilateral or contralateral to the infused amygdala (Fig. 6E; CA1 SO; ipsilateral: $\mathrm{NS}=12.7 \pm 3.4, \mathrm{KA}=7.8 \pm 1.5$, contralateral: $\mathrm{NS}=7.3 \pm 2.3, \mathrm{KA}=7.7 \pm 1.8$, mean \pm SEM, number of pY816+ neuronal processes). Likewise, stratum lacunosum moleculare contains the distal apical dendritic arbors of CA1 pyramidal cells, and this region exhibited few pY816+ neuronal processes (data not shown). No significant differences in the numbers of pY816+ neuronal processes were detected in this region between NS $(n=9)$ and $\mathrm{KA}(\mathrm{n}=9)$ treated animals (Fig. 6E; CA1 SLM; ipsilateral: $\mathrm{NS}=4.1 \pm 1.0, \mathrm{KA}=4.8 \pm 1.3$, contralateral: $\mathrm{NS}=4.1 \pm 0.8, \mathrm{KA}=5.2 \pm 1.5$, mean $\pm \mathrm{SEM}$, number of pY816+ neuronal processes). Finally, little pY816 immunoreactivity was detected in either apical or basal dendritic shafts of CA3 pyramids (in CA3 stratum radiatum and stratum oriens respectively) nor in apical dendritic shafts of dentate granule cells in either the suprapyramidal or infrapyramidal molecular layers of dentate gyrus (data not shown); no significant differences in the numbers of discerned neuronal processes between NS $(n=9)$ and KA $(n=9)$ infused animals were found in any of these regions (Fig. 6E; CA3 SR, CA3 SO, SML, and IML). Importantly, in each of the above regions, abundant GFP-labeled dendritic shafts were evident in Thy1 GFP animals (data not shown). Thus, apical but not basal dendritic shafts of CA1 pyramidal cells exhibited pY816 immunoreactivity under basal conditions, and this immunoreactivity increased following KA-SE; the immunoreactivity was detected within the proximal dendritic tree within stratum radiatum but not in the most distal portion within stratum lacunosum moleculare. Likewise, minimal pY816 immunoreactivity was detectable within the dendritic arbors of CA3 pyramids and dentate granule cells, nor were differences detected in NS compared to KA treated animals.

Similar increases of pY816 labeling of apical dendritic shafts of CA1 pyramidal cells were evident in mice after three hours of SE induced by intraperitoneal injection of pilocarpine. That is, a 6.2-fold increase in the number of pY816-immunoreactive apical shafts of CA1 pyramidal cells was evident in pilocarpine treated animals $(n=5)$ compared to NS $(n=4)$ (NS $=12.3 \pm 3.3$, Pilocarpine $=76.4 \pm 12.0$, mean \pm SEM, number of pY816+ neuronal processes; $p<0.01$ by Student's t-test). In contrast to the KA-SE model, apical shaft staining increased bilaterally within both hippocampi in all pilocarpine treated mice $(n=5)$ when compared to NS injected littermates (data not shown). As in the KA-SE model, examination of other regions within hippocampus revealed no detectable differences in the total number of pY816+ basal dendrites observed in stratum oriens of CA1 following SE, nor in any of the other hippocampal regions quantified in the KA-SE model (data not shown). 


\section{Characterization of pY816 immunoreactivity within apical dendritic shafts of pyramidal cells in CA1 following KA-SE}

The finding of increased pY816 immunoreactivity within apical dendritic shafts of CA1 pyramidal cells warranted further analysis of its location within these structures. Colocalization analysis with GFP+ shafts in hippocampi of KA-SE treated mice $(n=5)$ revealed immunoreactivity that appeared intracellular and punctate (Fig. 7A-I and Supplementary Fig. 4A-I; arrows). Further inspection of the distribution of pY816 immunoreactivity within apical dendritic shafts of CA1 pyramidal cells in SE treated animals in the KA microinfusion model revealed that this punctate immunoreactivity appeared most prominently within the portion proximal to the soma, becoming sparser and more difficult to identify with increased distance from stratum pyramidale (Fig. 6CD). Sections stained with MAP2 from KA-SE treated mice $(n=3)$ revealed apical shafts of CA1 pyramidal cells projecting throughout the entire stratum radiatum, and continuing into stratum lacunosum moleculare (Fig. 8A; arrows). Thus, this finding was not a result of large differences in the numbers of apical dendritic shafts populating proximal versus distal stratum radiatum, or because these shafts were not running parallel to the plane of section. As stated previously, few pY816+ neuronal processes were counted in stratum lacunosum moleculare and no increase was detected following SE (Fig. 6E; CA1 SLM), demonstrating that pY816 immunoreactivity was also not prominent within the most distal dendritic shafts of CA1 pyramidal cells that populate this region of hippocampus. pY816 immunoreactivity was generally most prominent within the primary apical shaft, with immunoreactivity much less noticeable within secondary branches (Fig. 7A-C and Supplementary Fig. 4A-C; arrow with dagger). Interestingly, the most proximal segments of primary apical dendrites of CA1 pyramidal cells are generally aspinous (Papp et al., 2001), and immunoreactivity was found within the shafts of these aspinous portions (Fig. 7D-F and Supplementary Fig. 4D-F; arrows), demonstrating that this immunoreactivity existed even when glutamatergic synapses were not in immediate proximity. However, dendritic immunoreactivity was also readily discernible on some spiny portions of dendritic shaft (Fig. 7G-I and Supplementary Fig. 4G-I; arrows).

To quantify the distance that pY816 immunoreactivity within the apical dendritic shaft was most prominent within stratum radiatum, GFP+ dendritic shafts containing pY816 immunoreactivity that could be traced throughout the entire vertical span of stratum radiatum were imaged, and the distance that this immunoreactivity was detectable within stratum radiatum was measured (Fig. 8B). In six such apical shafts taken from the ipsilateral hippocampus of a KA infused animal, pY816 immunoreactivity was detected an average of $78.7 \mu \mathrm{m}$ from the soma. In contrast, mean total dendritic shaft length within stratum radiatum was found to be $235.8 \mu \mathrm{m}$. Thus, pY816 immunoreactivity was readily detectable throughout only about $32 \%$ of the total apical shaft length within stratum radiatum (Fig. 8C). All of these findings demonstrate that pY816 TrkB immunoreactivity is enhanced within proximal shafts of apical dendrites of CA1 pyramidal cells following SE, and appears intracellular and punctate within these structures.

\section{Enhanced pY816 immunoreactivity within dendritic spines of pyramidal cells in CA1 stratum radiatum following $\mathrm{KA}-\mathrm{SE}$}

The localization of pY816 immunoreactive puncta to presynaptic boutons of mossy fiber axons within stratum lucidum raised the question as to whether pY816 immunoreactivity within CA1 might be localized to synaptic specializations of the apical dendrites of CA1 pyramidal cells. Small specializations of apical dendrites of CA1 pyramidal cells indicative of spines were evident in Thy1 GFP mice in both NS and KA infused animals. Moreover, analysis of pY816 immunoreactivity within stratum radiatum of CA1 revealed that, in addition to signal corresponding to apical dendritic shafts, the entire region was also filled 
with many small puncta. Inspection of GFP+ spines of apical dendrites in Thy1 GFP mice revealed that a subset colocalized with pY816 puncta (Fig. 9A-I and Supplementary Fig. 5A-I; arrows). To quantify colocalization of pY816 immunoreactivity with GFP+ dendritic spines in CA1 stratum radiatum, $z$-stacks were acquired and spines scored as positive or negative for pY816 by a blinded observer; a spine was scored as positive if filled with a pY816 immunoreactive puncta in at least one $z$-section. Over 1800 spines were examined in the same NS ( $n=5)$ and SE ( $n=5)$ Thy1 GFP animals used previously in this study. The percentages of pY816+ spines in CA1 stratum radiatum in NS and KA treated mice both ipsilateral and contralateral to infusion was then determined (Fig. 9J; CA1 SR). Importantly, no overt differences in spines were noticeable between conditions (data not shown).

Under basal conditions, a small fraction (approximately 10\%) of spines of proximal apical dendrites of CA1 pyramidal cells exhibited pY816 immunoreactivity. The fraction of GFP+ spines exhibiting pY816 immunoreactivity approximately doubled in the apical dendrites of CA1 pyramidal cells in the hippocampus ipsilateral to the amygdala infused with KA (NS = $10.7 \pm 1.4 \%, \mathrm{SE}=21.0 \pm 2.7 \%$, mean $\pm \mathrm{SEM} ; \mathrm{p}<0.01$ ); a 1.6 -fold increase was detected in the hippocampus contralateral to the infused amygdala (NS $=10.4 \pm 1.1 \%, \mathrm{SE}=16.9 \pm$ $1.9 \%$, mean \pm SEM, $\mathrm{p}>0.05$ ). The percentage of $\mathrm{pY} 816$ colocalization with spines in stratum radiatum of CA1 in KA infused animals was always greater in hippocampus ipsilateral to the infused amygdala compared to contralateral and this value always exceeded that found in either hippocampus of NS infused littermates $(n=5)$. Thus, similar to giant boutons of the mossy fiber-CA3 synapse, pY816 immunoreactivity was found to increase in spines of the CA3-CA1 synapse following SE induced by KA microinfusion, and this effect was lateralized to the side ipsilateral to infusion.

As GFP+ spines could also be visualized in stratum oriens of CA1 and stratum lacunosum moleculare in these same mice (data not shown), similar analyses were conducted in these regions (Fig. 9J; CA1 SO and CA1 SLM). Similar to stratum radiatum of CA1, pY816 puncta could be discerned within these regions and colocalized with a subset (approximately $10 \%$ ) of GFP+ spines (data not shown). However, unlike stratum radiatum of CA1, no significant differences in the numbers of pY816 immunoreactive spines on basal dendrites within stratum oriens of CA1 were detected between NS ( $n=5)$ and KA animals ( $n=5)$, either ipsilateral or contralateral to infusion (ipsilateral: $\mathrm{NS}=10.3 \pm 1.0 \%, \mathrm{KA}=10.0 \pm 0.7 \%$, contralateral: $\mathrm{NS}=10.0 \pm 1.4 \%, \mathrm{KA}=10.4 \pm 0.5 \%$, mean $\pm \mathrm{SEM} ; \mathrm{p}>0.05)$. Similar results were obtained with quantification of spines of apical dendrites of CA1 pyramidal neurons within stratum lacunosum moleculare (ipsilateral: $\mathrm{NS}=11.7 \pm 1.7 \%, \mathrm{KA}=12.9 \pm 2.7 \%$, contralateral: $\mathrm{NS}=10.6 \pm 0.9 \%, \mathrm{KA}=15.9 \pm 1.9 \%$, mean $\pm \mathrm{SEM} ; \mathrm{p}>0.05 ; \mathrm{n}=5$ mice per treatment group). Thus, pY816 activation within spines of CA1 pyramidal neurons following SE appeared to be confined to the proximal apical dendrites within stratum radiatum, just as increased pY816+ immunoreactivity was also only found within this portion of the dendritic tree of CA1 pyramidal neurons.

Finally, GFP+ spines of CA3 pyramids were readily discerned within stratum radiatum of CA3, and spines of dentate granule cells could be imaged in the dentate gyrus (data not shown). This afforded the opportunity to quantify pY816 immunoreactivity in spines within these other important neuronal populations of hippocampus. Quantification of spines in CA3 stratum radiatum demonstrated that about $10 \%$ of spines were found to contain significant pY816 immunoreactivity, but no differences were found between NS $(n=5)$ and KA $(n=5)$ conditions on either side relative to infusion (Fig. 9J; CA3 SR; $p>0.05$ ). For spines of the molecular layer of dentate gyrus, the outer two-thirds of this region was quantified, as this is the portion that receives perforant path innervation from entorhinal cortex and is robustly activated during limbic seizures. Quantification of both suprapyramidal and infrapyramidal molecular layers demonstrated that approximately 9\% of imaged spines contained pY816 
immunoreactivity in NS treated mice $(n=5)$, and there was no significant increase in this percentage in KA-SE treated animals $(n=5)$ (Fig. 9J; SML and IML; $p>0.05)$. Thus, enhanced pY816 immunoreactivity within synaptic spines appeared to be confined only to stratum radiatum in hippocampus following KA-SE, the only region where increases in pY816 immunoreactivity were found in dendritic shafts after SE. Furthermore, the only regions where increases in immunoreactivity within synaptic boutons or spines was detected were also the only regions where increases in pY816 immunoreactivity within axons or dendritic shafts was detected, namely stratum lucidum and stratum radiatum of CA1.

\section{DISCUSSION}

This study tested the hypothesis that enhanced pTrkB immunoreactivity evident in the hippocampus in multiple animal models was localized to the mossy fibers of dentate granule cells. To test this hypothesis, confocal microscopy was employed to examine colocalization of pY816 immunoreactivity with axonal and dendritic markers, and with GFP expressed in hippocampal neurons of Thy1 GFP mice following SE. Four principal findings emerged: (1) pY816 immunoreactivity in stratum lucidum was found within mossy fiber axons and giant presynaptic boutons of dentate granule cells of control adult mice. (2) A robust increase of pY816 immunoreactivity was detected within both of these structures following SE. (3) Unexpectedly, pY816 immunoreactivity was also found within the shafts and spines of apical dendrites of CA1 pyramidal cells of control adult mice. (4) pY816 immunoreactivity was also robustly enhanced within these structures following SE. Collectively, these findings provide evidence that $\mathrm{SE}$ induces enhanced activation of TrkB at two distinct excitatory synapses within hippocampal circuitry. This enhanced TrkB activation is well positioned to regulate the plasticity of these synapses, an attractive cellular mechanism underlying epileptogenesis.

The results reveal that activated TrkB within hippocampus is most prominent within stratum lucidum, and robustly increases within this region following KA-SE. The activated TrkB within stratum lucidum was localized to the axons and giant boutons of the mossy fibers of dentate granule cells by colocalization of pY816 immunoreactivity with GFP expressed in these neurites, and confirmed by colocalization with the axonal marker, tau. Whereas all mossy fiber axons appeared to contain activated TrkB, only a small minority (5\%) of mossy fiber boutons contained activated TrkB under basal conditions. Notably, a striking 4-fold increase was found in the percentage of mossy fiber boutons containing activated TrkB in the hippocampus ipsilateral to KA infusion. These results confirm earlier work that reported increased pTrkB immunoreactivity in stratum lucidum during epileptogenesis, yet was unable to identify the cellular structures containing this immunoreactivity (Binder et al., 1999a; Danzer et al., 2004; He et al., 2004; He et al., 2002; He et al., 2010). The present results are also consistent with recent ultrastructural evidence localizing pY816 immunoreactivity to mossy fiber axons and a minority (5\%) of boutons within SL under basal conditions (Spencer-Segal et al., 2011); pY816 immunoreactivity within boutons was most often affiliated with small synaptic vesicles opposite the synaptic contact.

The abundance of activated TrkB found in stratum lucidum correlates with high levels of expression of ligands known to activate it. The highest levels in forebrain of the canonical TrkB ligand, BDNF, are found within stratum lucidum, where its expression is increased during epileptogenesis (Conner et al., 1997; He et al., 2004; Yan et al., 1997). Unexpectedly, increases of activated TrkB within stratum lucidum were identified during epileptogenesis despite conditional deletion of BDNF (He et al., 2004), a finding leading to the discovery that the divalent cation, zinc, can transactivate TrkB in the absence of BDNF (Huang and McNamara, 2010; Huang et al., 2008). Synaptic vesicles of mossy fiber boutons contain copious stores of zinc, presumably released during neuronal activity, suggesting a role for 
this metal in contributing to TrkB activation at this locale (Cole et al., 1999; Qian and Noebels, 2005). pTrkB within mossy fiber boutons is likely to have been activated at the synaptic membrane by one of these ligands. The pTrkB within axons may be in transit back to the soma; retrograde transport of pTrk-ligand complexes have been previously described in axons and may promote communication of TrkB signaling from synapse to cell body (Bhattacharyya et al., 1997; Watson et al., 1999) in a manner similar to NGF-TrkA signaling (Niewiadomska et al., 2011).

The discovery of activated TrkB within shafts of apical dendrites and spines of CA1 pyramidal cells following epileptogenesis was unexpected based upon previous work (Binder et al., 1999a; Danzer et al., 2004; He et al., 2004; He et al., 2002; He et al., 2010). Use of less sensitive antibodies together with quantitative analyses conducted solely at low magnification $(100 \times)$ accounts for this finding previously escaping detection. Indeed, quantification at low power $(100 \times)$ in stratum radiatum of CA1 in the present study revealed no significant differences between NS and KA treated animals, despite robust increases following KA when pY816+ dendritic shafts and spines were quantified at high power (630x). These results are consistent with ultrastructural evidence localizing pY816 immunoreactivity to dendritic shafts of CA1 pyramids and a minority (5\%) of spines within stratum radiatum of CA1 under basal conditions (Spencer-Segal et al., 2011); notably, activated TrkB was clustered next to the postsynaptic density. Light microscopic studies have also colocalized pTrkB immunoreactivity with a subset of PSD-95 (5\%) in stratum radiatum of CA1, and the fraction of pTrkB colocalizing with PSD-95 increased approximately 2 -fold following an unsupervised learning paradigm (Chen et al., 2010a; Chen et al., 2010b). These values are similar to those detected under basal conditions in the present study. Notably, BDNF and synaptic zinc are readily detectable within stratum radiatum of CA1, but are present in lower amounts than in stratum lucidum, correlating with the less robust pY816 immunoreactivity detected in this region (Conner et al., 1997; Yan et al., 1997). Like in mossy fiber boutons, TrkB at the spine is likely to be activated by one of these ligands, and pTrkB within dendritic shafts may be undergoing retrograde transport to the soma.

The restricted localization of activated TrkB induced by SE raises multiple questions. Why is the activation not more widespread? And what accounts for its activation within synapses at these two sites? With respect to the first question, we suspect that enhanced TrkB activation does indeed occur at sites outside the hippocampus and perhaps even at additional sites within hippocampus. The present study examined TrkB activation at a single point in time, following 3 hours of SE; study at additional times following SE might reveal additional sites of TrkB activation. Moreover, an antibody with greater sensitivity may have revealed additional sites of TrkB activation even at 3 hours. With respect to the second question, we favor the explanation that enhanced release of BDNF and/or zinc from presynaptic terminals of axons of the dentate granule cells and CA3 pyramidal cells is responsible for TrkB activation in mossy fiber boutons and CA1 pyramidal cell spines respectively. That is, SE, the inducing stimulus, is characterized by enhanced firing of populations of neurons which would be expected to trigger release of BDNF and zinc which are packaged in synaptic vesicles. The localization of activated TrkB to synapses is consistent with this idea. The bilateral tonic and clonic motor activity of the induced seizures notwithstanding, the lateralization of activated TrkB preferentially to the hippocampus ipsilateral to the infused amygdala is consistent with enhanced neuronal activity within these circuits, a proposal consistent with direct projection ipsilaterally—but not contralaterallyfrom the basal nucleus of amygdala to CA3 and CA1 of hippocampus (Pikkarainen et al., 1999). 
This idea may also account for the localization of pY816 immunoreactivity to the spines and shafts of proximal apical dendrites, while sparing the spines and shafts of basilar dendrites and of the distal portion of apical dendrites within stratum lacunosummoleculare. The observed distribution of TrkB activation implies that afferents innervating the apical dendrites of CA1 pyramidal cells were activated during KA-SE to a greater extent than those innervating the basilar dendrites. Interestingly, axons of CA3 pyramidal neurons positioned closer to dentate gyrus (CA3c) project preferentially to superficial layers of stratum radiatum of CA1 (located closer to stratum lacunosum moleculare) (Ishizuka et al., 1990). In contrast, axons of CA3 pyramidal cells located closer to CA1 (in CA3a) project preferentially to proximal apical dendrites of CA1 pyramidal cells and to basilar dendrites in stratum oriens. These differential patterns of anatomic projections support the possibility that preferential firing of subpopulations of CA3 pyramidal cells during KA-SE may promote release of TrkB ligands from subpopulations of synapses formed by CA3 axons on spines of proximal apical dendrites of CA1 pyramidal cells, thereby accounting for the observed pattern of pY816 immunoreactivity.

Activation of TrkB within these hippocampal neuronal populations likely promotes epileptogenesis, though study of this process in mutant mice carrying cell type specific deletions of TrkB will be required to provide definitive answers. Lesion studies implicate hippocampal circuitry in epileptogenesis triggered by stimulation of amygdala in the kindling model as evidenced by striking inhibition following knife cuts of entorhinal cortex or selective destruction of the dentate granule cells (Dasheiff and McNamara, 1982; Savage et al., 1985). With respect to how TrkB activation at these locales may contribute to the development of epilepsy, one cellular consequence of activated TrkB in mossy fibers that might promote epileptogenesis is long term potentiation (LTP). Both ex vivo and in vivo studies of animal models support the idea that LTP of excitatory synapses between principal cells contributes to limbic epileptogenesis (Sutula and Steward, 1987), the hypothesis being that potentiation of these synapses may facilitate propagation of seizure activity via synaptically coupled neuronal populations throughout the limbic system and beyond.

The excitatory synapse formed by mossy fiber boutons with spines of CA3 pyramids undergoes LTP which is notable in that mechanisms underlying its induction and expression reside presynaptically (reviewed by Nicoll and Schmitz, 2005; Pan et al. 2011; but see Yeckel et al. 1999). Mossy fiber-CA3 LTP is eliminated by inhibition of TrkB kinase (Huang et al., 2008) and by inhibition of TrkB-mediated activation of phospholipase C gamma-1 (PLC $\gamma 1$ ) signaling through pY816 (He et al., 2010), the same residue critical for epileptogenesis. Interestingly, study of hippocampal slices isolated from animals following KA induced seizures in vivo revealed that LTP of the mossy fiber-CA3 synapse was occluded, suggesting that this synapse had undergone LTP in vivo (Goussakov et al., 2000). Collectively, it seems plausible that enhanced activation of TrkB in mossy fibers may contribute to LTP of this synapse in vivo during epileptogenesis. The axonal localization of pY816 immunoreactivity within stratum lucidum is also consistent with the possibility that TrkB-PLC $\gamma 1$ signaling within these structures, through evoking rises in cytosolic calcium, is positioned to promote LTP by activating type 2 ryanodine receptors. These ER-bound channels mediate calcium-induced calcium release (CICR) from internal stores, and themselves open in response to rises in calcium (Verkhratsky, 2005). These receptors have been localized to mossy fiber axons (Shimizu et al., 2008) in a distribution similar to pY816 found in this study. Mossy fiber-CA3 LTP is inhibited by ryanodine (Bortolotto et al., 2003), consistent with the idea that type 2 ryanodine receptor activation may be a consequence of pY816 signaling. Interestingly, epileptic seizures are one manifestation of mice genetically engineered to express leaky type 2 ryanodine receptors (Lehnart et al., 2008). 
Like activated TrkB within mossy fiber boutons, one cellular consequence of the enhanced TrkB activation within spines of CA1 pyramidal cells may be LTP of synapses formed by Schaffer collateral axon terminals onto these structures (Huang et al., 2008; Minichiello et al., 1999). TrkB activation at these synapses has been implicated in both LTP and hippocampal-dependent associative learning (Gruart et al., 2007). Like the mossy fiber-CA3 synapse, mutation of Y816, but not Y515, inhibited induction of LTP of the Schaffer collateral-CA1 synapse (He et al., 2010; Korte et al., 2000; Minichiello et al., 2002), the same residue implicated in promoting epileptogenesis. Furthermore, in immunohistochemical studies examining pTrkB using brain slices treated with LTPinducing stimuli at the Schaffer collateral-CA1 synapse, increases in numbers of pTrkBimmunoreactive puncta were observed in CA1 stratum radiatum (Lu et al., 2011), and enhanced colocalization of pTrkB puncta with PSD-95 was found in brain slices after such a stimuli (Chen et al., 2010b). The location of activated TrkB within spines of CA1 pyramidal neurons is optimally positioned to promote a postsynaptic LTP of this synapse. Whereas the pTrkB found within dendritic spines in the present study is well positioned to regulate synaptic function $(\mathrm{Lu}, 2003)$, the function of pTrkB within shafts is less obvious. If pTrkB within dendritic shafts is in transit back to the soma, it may ultimately affect key transcriptional regulators, such as CREB, implicated in the expression of the late phase of LTP, which is protein synthesis dependent and also mediated by TrkB (Minichiello, 2009).

In summary, the present work demonstrates that epileptogenesis is associated with a highly specific pattern of enhanced activation of TrkB within hippocampus. Among the diverse populations of neurons within hippocampus, enhanced activation of TrkB was identified only within DGCs and CA1 pyramids, suggesting that the functional consequences of its activation are multifocal yet discrete within limbic circuitry. The localization within these populations was highly specific, involving the axons of the granule cells and apical, but not basal, dendritic shafts of CA1 pyramids. While localization to synapses was common to each population of neurons, the localization was to presynaptic boutons of the granule cell axons and to postsynaptic spines of the CA1 pyramids. One plausible cellular consequence of enhanced TrkB activation is increased efficacy of excitatory synapses between principal neurons, a cellular event likely pivotal to the pathogenesis of limbic epilepsy.

\section{Supplementary Material}

Refer to Web version on PubMed Central for supplementary material.

\section{Acknowledgments}

Support:

This work was supported by grants from NINDS NS056217 (J.O.M) and the Wakeman Endowment through the Wakeman Award at Duke University (J.H.).

The authors thank Drs. Yang Zhong Huang and A. Soren Leonard for helpful comments on the manuscript, and Wei-Hua Qian for assistance with mouse husbandry and genotyping.

\section{ROLE OF AUTHORS}

All authors had full access to all the data in the study and take responsibility for the integrity of the data and the accuracy of the data analysis. Study concept and design: Jeffrey Helgager and James O. McNamara. Acquisition of data: Jeffrey Helgager. Analysis and interpretation of data: Jeffrey Helgager and James O. McNamara. Drafting of the manuscript: Jeffrey Helgager and James O. McNamara. Critical revision of the manuscript for important intellectual content: Jeffrey Helgager, Gumei Liu, and James O. McNamara. Statistical analysis: Jeffrey Helgager. Obtained funding: Jeffrey Helgager and James O. McNamara. Administrative, technical, and material support: Jeffrey Helgager, Gumei Liu, and James O. McNamara. Study supervision: James O. McNamara. 


\section{LITERATURE CITED}

Abramoff MD, Magelhaes PJ, Ram SJ. Image Processing with ImageJ. Biophotonics International. 2004; 11(7):36-42.

Amaral DG, Dent JA. Development of the mossy fibers of the dentate gyrus: I. A light and electron microscopic study of the mossy fibers and their expansions. The Journal of comparative neurology. 1981; 195(1):51-86. [PubMed: 7204652]

Annegers JF, Hauser WA, Elveback LR, Kurland LT. The risk of epilepsy following febrile convulsions. Neurology. 1979; 29(3):297-303. [PubMed: 571973]

Araki T, Simon RP, Taki W, Lan JQ, Henshall DC. Characterization of neuronal death induced by focally evoked limbic seizures in the C57BL/6 mouse. J Neurosci Res. 2002; 69(5):614-621. [PubMed: 12210827]

Arroyo S, Brodie MJ, Avanzini G, Baumgartner C, Chiron C, Dulac O, French JA, Serratosa JM. Is refractory epilepsy preventable? Epilepsia. 2002; 43(4):437-444. [PubMed: 11952776]

Bhattacharyya A, Watson FL, Bradlee TA, Pomeroy SL, Stiles CD, Segal RA. Trk receptors function as rapid retrograde signal carriers in the adult nervous system. J Neurosci. 1997; 17(18):7007-7016. [PubMed: 9278536]

Binder DK, Routbort MJ, McNamara JO. Immunohistochemical evidence of seizure-induced activation of trk receptors in the mossy fiber pathway of adult rat hippocampus. J Neurosci. 1999a; 19(11):4616-4626. [PubMed: 10341259]

Binder DK, Routbort MJ, Ryan TE, Yancopoulos GD, McNamara JO. Selective inhibition of kindling development by intraventricular administration of TrkB receptor body. J Neurosci. 1999b; 19(4): 1424-1436. [PubMed: 9952419]

Binder LI, Frankfurter A, Rebhun LI. The distribution of tau in the mammalian central nervous system. J Cell Biol. 1985; 101(4):1371-1378. [PubMed: 3930508]

Bortolotto ZA, Lauri S, Isaac JT, Collingridge GL. Kainate receptors and the induction of mossy fibre long-term potentiation. Philos Trans R Soc Lond B Biol Sci. 2003; 358(1432):657-666. [PubMed: 12740111]

Chen LY, Rex CS, Pham DT, Lynch G, Gall CM. BDNF signaling during learning is regionally differentiated within hippocampus. J Neurosci. 2010a; 30(45):15097-15101. [PubMed: 21068315]

Chen LY, Rex CS, Sanaiha Y, Lynch G, Gall CM. Learning induces neurotrophin signaling at hippocampal synapses. Proc Natl Acad Sci U S A. 2010b; 107(15):7030-7035. [PubMed: 20356829]

Cole TB, Wenzel HJ, Kafer KE, Schwartzkroin PA, Palmiter RD. Elimination of zinc from synaptic vesicles in the intact mouse brain by disruption of the ZnT3 gene. Proc Natl Acad Sci U S A. 1999; 96(4):1716-1721. [PubMed: 9990090]

Conner JM, Lauterborn JC, Yan Q, Gall CM, Varon S. Distribution of brain-derived neurotrophic factor (BDNF) protein and mRNA in the normal adult rat CNS: evidence for anterograde axonal transport. J Neurosci. 1997; 17(7):2295-2313. [PubMed: 9065491]

Copanaki E, Chang S, Vlachos A, Tschape JA, Muller UC, Kogel D, Deller T. sAPPalpha antagonizes dendritic degeneration and neuron death triggered by proteasomal stress. Mol Cell Neurosci. 2010; 44(4):386-393. [PubMed: 20472066]

Croll SD, Suri C, Compton DL, Simmons MV, Yancopoulos GD, Lindsay RM, Wiegand SJ, Rudge JS, Scharfman HE. Brain-derived neurotrophic factor transgenic mice exhibit passive avoidance deficits, increased seizure severity and in vitro hyperexcitability in the hippocampus and entorhinal cortex. Neuroscience. 1999; 93(4):1491-1506. [PubMed: 10501474]

Danzer SC, He X, McNamara JO. Ontogeny of seizure-induced increases in BDNF immunoreactivity and TrkB receptor activation in rat hippocampus. Hippocampus. 2004; 14(3):345-355. [PubMed: 15132434]

Danzer SC, Kotloski RJ, Walter C, Hughes M, McNamara JO. Altered morphology of hippocampal dentate granule cell presynaptic and postsynaptic terminals following conditional deletion of TrkB. Hippocampus. 2008; 18(7):668-678. [PubMed: 18398849] 
Danzer SC, McNamara JO. Localization of brain-derived neurotrophic factor to distinct terminals of mossy fiber axons implies regulation of both excitation and feedforward inhibition of CA3 pyramidal cells. J Neurosci. 2004; 24(50):11346-11355. [PubMed: 15601941]

Dasheiff RM, McNamara JO. Intradentate colchicine retards the development of amygdala kindling. Ann Neurol. 1982; 11(4):347-352. [PubMed: 7103415]

Dunleavy M, Shinoda S, Schindler C, Ewart C, Dolan R, Gobbo OL, Kerskens CM, Henshall DC. Experimental neonatal status epilepticus and the development of temporal lobe epilepsy with unilateral hippocampal sclerosis. Am J Pathol. 2010; 176(1):330-342. [PubMed: 19948825]

Feng G, Mellor RH, Bernstein M, Keller-Peck C, Nguyen QT, Wallace M, Nerbonne JM, Lichtman JW, Sanes JR. Imaging neuronal subsets in transgenic mice expressing multiple spectral variants of GFP. Neuron. 2000; 28(1):41-51. [PubMed: 11086982]

Goussakov IV, Fink K, Elger CE, Beck H. Metaplasticity of mossy fiber synaptic transmission involves altered release probability. J Neurosci. 2000; 20(9):3434-3441. [PubMed: 10777806]

Gowers, WR. Epilepsy and other chronic convulsive diseases: their causes, symptoms, \& treatment. London: Churchill; 1881. p. 309xiv

Gruart A, Sciarretta C, Valenzuela-Harrington M, Delgado-Garcia JM, Minichiello L. Mutation at the TrkB PLC \{gamma $\}$-docking site affects hippocampal LTP and associative learning in conscious mice. Learn Mem. 2007; 14(1):54-62. [PubMed: 17272652]

He XP, Kotloski R, Nef S, Luikart BW, Parada LF, McNamara JO. Conditional deletion of TrkB but not BDNF prevents epileptogenesis in the kindling model. Neuron. 2004; 43(1):31-42. [PubMed: 15233915]

He XP, Minichiello L, Klein R, McNamara JO. Immunohistochemical evidence of seizure-induced activation of trkB receptors in the mossy fiber pathway of adult mouse hippocampus. J Neurosci. 2002; 22(17):7502-7508. [PubMed: 12196573]

He XP, Pan E, Sciarretta C, Minichiello L, McNamara JO. Disruption of TrkB-mediated phospholipase Cgamma signaling inhibits limbic epileptogenesis. J Neurosci. 2010; 30(18):61886196. [PubMed: 20445044]

Huang YZ, McNamara JO. Mutual regulation of Src family kinases and the neurotrophin receptor TrkB. J Biol Chem. 2010; 285(11):8207-8217. [PubMed: 20064930]

Huang YZ, Pan E, Xiong ZQ, McNamara JO. Zinc-mediated transactivation of TrkB potentiates the hippocampal mossy fiber-CA3 pyramid synapse. Neuron. 2008; 57(4):546-558. [PubMed: 18304484]

Huber G, Matus A. Differences in the cellular distributions of two microtubule-associated proteins, MAP1 and MAP2, in rat brain. J Neurosci. 1984; 4(1):151-160. [PubMed: 6198491]

Ishizuka N, Weber J, Amaral DG. Organization of intrahippocampal projections originating from CA3 pyramidal cells in the rat. J Comp Neurol. 1990; 295(4):580-623. [PubMed: 2358523]

Kasugai M, Akaike K, Imamura S, Matsukubo H, Tojo H, Nakamura M, Tanaka S, Sano A. Differences in two mice strains on kainic acid-induced amygdalar seizures. Biochem Biophys Res Commun. 2007; 357(4):1078-1083. [PubMed: 17467670]

Kokaia M, Ernfors P, Kokaia Z, Elmer E, Jaenisch R, Lindvall O. Suppressed epileptogenesis in BDNF mutant mice. Exp Neurol. 1995; 133(2):215-224. [PubMed: 7649227]

Korte M, Minichiello L, Klein R, Bonhoeffer T. Shc-binding site in the TrkB receptor is not required for hippocampal long-term potentiation. Neuropharmacology. 2000; 39(5):717-724. [PubMed: 10699438]

Lehnart SE, Mongillo M, Bellinger A, Lindegger N, Chen BX, Hsueh W, Reiken S, Wronska A, Drew LJ, Ward CW, Lederer WJ, Kass RS, Morley G, Marks AR. Leaky Ca2+ release channel/ ryanodine receptor 2 causes seizures and sudden cardiac death in mice. J Clin Invest. 2008; 118(6):2230-2245. [PubMed: 18483626]

Li T, Ren G, Lusardi T, Wilz A, Lan JQ, Iwasato T, Itohara S, Simon RP, Boison D. Adenosine kinase is a target for the prediction and prevention of epileptogenesis in mice. J Clin Invest. 2008; 118(2): 571-582. [PubMed: 18172552]

Loscher W. Animal models of epilepsy for the development of antiepileptogenic and diseasemodifying drugs. A comparison of the pharmacology of kindling and post-status epilepticus models of temporal lobe epilepsy. Epilepsy Res. 2002; 50(1-2):105-123. [PubMed: 12151122] 
Lu B. BDNF and activity-dependent synaptic modulation. Learn Mem. 2003; 10(2):86-98. [PubMed: 12663747]

Lu Y, Ji Y, Ganesan S, Schloesser R, Martinowich K, Sun M, Mei F, Chao MV, Lu B. TrkB as a potential synaptic and behavioral tag. J Neurosci. 2011; 31(33):11762-11771. [PubMed: 21849537]

Mathern, GW.; Babb, TL.; Armstrong, DL. Hippocampal Sclerosis. In: Engel, J.; Pedley, TA., editors. Epilepsy : a comprehensive textbook. Philadelphia: Lippincott-Raven; 1997. p. 133-155.

Minichiello L. TrkB signalling pathways in LTP and learning. Nat Rev Neurosci. 2009; 10(12):850860. [PubMed: 19927149]

Minichiello L, Calella AM, Medina DL, Bonhoeffer T, Klein R, Korte M. Mechanism of TrkBmediated hippocampal long-term potentiation. Neuron. 2002; 36(1):121-137. [PubMed: 12367511]

Minichiello L, Korte M, Wolfer D, Kuhn R, Unsicker K, Cestari V, Rossi-Arnaud C, Lipp HP, Bonhoeffer T, Klein R. Essential role for TrkB receptors in hippocampus-mediated learning. Neuron. 1999; 24(2):401-414. [PubMed: 10571233]

Mouri G, Jimenez-Mateos E, Engel T, Dunleavy M, Hatazaki S, Paucard A, Matsushima S, Taki W, Henshall DC. Unilateral hippocampal CA3-predominant damage and short latency epileptogenesis after intra-amygdala microinjection of kainic acid in mice. Brain Res. 2008; 1213:140-151. [PubMed: 18455706]

Nicoll RA, Schmitz D. Synaptic plasticity at hippocampal mossy fibre synapses. Nat Rev Neurosci. 2005; 6(11):863-876. [PubMed: 16261180]

Niewiadomska G, Mietelska-Porowska A, Mazurkiewicz M. The cholinergic system, nerve growth factor and the cytoskeleton. Behav Brain Res. 2011; 221(2):515-526. [PubMed: 20170684]

Pan E, Zhang XA, Huang Z, Krezel A, Zhao M, Tinberg CE, Lippard SJ, McNamara JO. Vesicular zinc promotes presynaptic and inhibits postsynaptic long-term potentiation of mossy fiber-CA3 synapse. Neuron. 2011; 71(6):1116-1126. [PubMed: 21943607]

Papp E, Leinekugel X, Henze DA, Lee J, Buzsaki G. The apical shaft of CA1 pyramidal cells is under GABAergic interneuronal control. Neuroscience. 2001; 102(4):715-721. [PubMed: 11182239]

Pikkarainen M, Ronkko S, Savander V, Insausti R, Pitkanen A. Projections from the lateral, basal, and accessory basal nuclei of the amygdala to the hippocampal formation in rat. J Comp Neurol. 1999; 403(2):229-260. [PubMed: 9886046]

Qian J, Noebels JL. Visualization of transmitter release with zinc fluorescence detection at the mouse hippocampal mossy fibre synapse. J Physiol. 2005; 566(Pt 3):747-758. [PubMed: 15919713]

Ramón y Cajal, S. Histologie du système nerveux de l'homme \& des vertébrés. Paris: Maloine; 1911.

Savage DD, Rigsbee LC, McNamara JO. Knife cuts of entorhinal cortex: effects on development of amygdaloid kindling and seizure-induced decrease of muscarinic cholinergic receptors. J Neurosci. 1985; 5(2):408-413. [PubMed: 3973674]

Sayin U, Osting S, Hagen J, Rutecki P, Sutula T. Spontaneous seizures and loss of axo-axonic and axo-somatic inhibition induced by repeated brief seizures in kindled rats. J Neurosci. 2003; 23(7): 2759-2768. [PubMed: 12684462]

Schauwecker PE, Steward O. Genetic determinants of susceptibility to excitotoxic cell death: implications for gene targeting approaches. Proc Natl Acad Sci U S A. 1997; 94(8):4103-4108. [PubMed: 9108112]

Segal RA, Bhattacharyya A, Rua LA, Alberta JA, Stephens RM, Kaplan DR, Stiles CD. Differential utilization of Trk autophosphorylation sites. J Biol Chem. 1996; 271(33):20175-20181. [PubMed: 8702742]

Shimizu H, Fukaya M, Yamasaki M, Watanabe M, Manabe T, Kamiya H. Use-dependent amplification of presynaptic $\mathrm{Ca} 2+$ signaling by axonal ryanodine receptors at the hippocampal mossy fiber synapse. Proc Natl Acad Sci U S A. 2008; 105(33):11998-12003. [PubMed: 18687898]

Spencer-Segal JL, Waters EM, Bath KG, Chao MV, McEwen BS, Milner TA. Distribution of Phosphorylated TrkB Receptor in the Mouse Hippocampal Formation Depends on Sex and Estrous Cycle Stage. J Neurosci. 2011; 31(18):6780-6790. [PubMed: 21543608] 
Sutula T, Steward O. Facilitation of kindling by prior induction of long-term potentiation in the perforant path. Brain Res. 1987; 420(1):109-117. [PubMed: 3676745]

Tsai MH, Chuang YC, Chang HW, Chang WN, Lai SL, Huang CR, Tsai NW, Wang HC, Lin YJ, Lu CH. Factors predictive of outcome in patients with de novo status epilepticus. Qjm. 2009; 102(1): 57-62. [PubMed: 19015144]

VanLandingham KE, Heinz ER, Cavazos JE, Lewis DV. Magnetic resonance imaging evidence of hippocampal injury after prolonged focal febrile convulsions. Ann Neurol. 1998; 43(4):413-426. [PubMed: 9546321]

Verkhratsky A. Physiology and pathophysiology of the calcium store in the endoplasmic reticulum of neurons. Physiol Rev. 2005; 85(1):201-279. [PubMed: 15618481]

Walter C, Murphy BL, Pun RY, Spieles-Engemann AL, Danzer SC. Pilocarpine-induced seizures cause selective time-dependent changes to adult-generated hippocampal dentate granule cells. $\mathrm{J}$ Neurosci. 2007; 27(28):7541-7552. [PubMed: 17626215]

Watson FL, Heerssen HM, Moheban DB, Lin MZ, Sauvageot CM, Bhattacharyya A, Pomeroy SL, Segal RA. Rapid nuclear responses to target-derived neurotrophins require retrograde transport of ligand-receptor complex. J Neurosci. 1999; 19(18):7889-7900. [PubMed: 10479691]

Xu B, Michalski B, Racine RJ, Fahnestock M. The effects of brain-derived neurotrophic factor (BDNF) administration on kindling induction, Trk expression and seizure-related morphological changes. Neuroscience. 2004; 126(3):521-531. [PubMed: 15183502]

Yan Q, Rosenfeld RD, Matheson CR, Hawkins N, Lopez OT, Bennett L, Welcher AA. Expression of brain-derived neurotrophic factor protein in the adult rat central nervous system. Neuroscience. 1997; 78(2):431-448. [PubMed: 9145800]

Yeckel MF, Kapur A, Johnston D. Multiple forms of LTP in hippocampal CA3 neurons use a common postsynaptic mechanism. Nat Neurosci. 1999; 2(7):625-633. [PubMed: 10404192] 
Confocal micrograph of hippocampus in a mouse which expresses a GFP transgene, labeling a subset of dentate granule cells as well as other neuronal populations (green), and stained with an antibody probing for phosphorylated tyrosine 816 (pY816) of the TrkB receptor (red). The mouse underwent three hours of status epilepticus induced by infusion of kainic acid into the right amygdala, resulting in greatly enhanced pY816 immunoreactivity, a surrogate measure of receptor activation. Overlap of pY816 with GFP-labeled mossy fibers (yellow) reveals colocalization of immunoreactivity with the mossy fibers. 


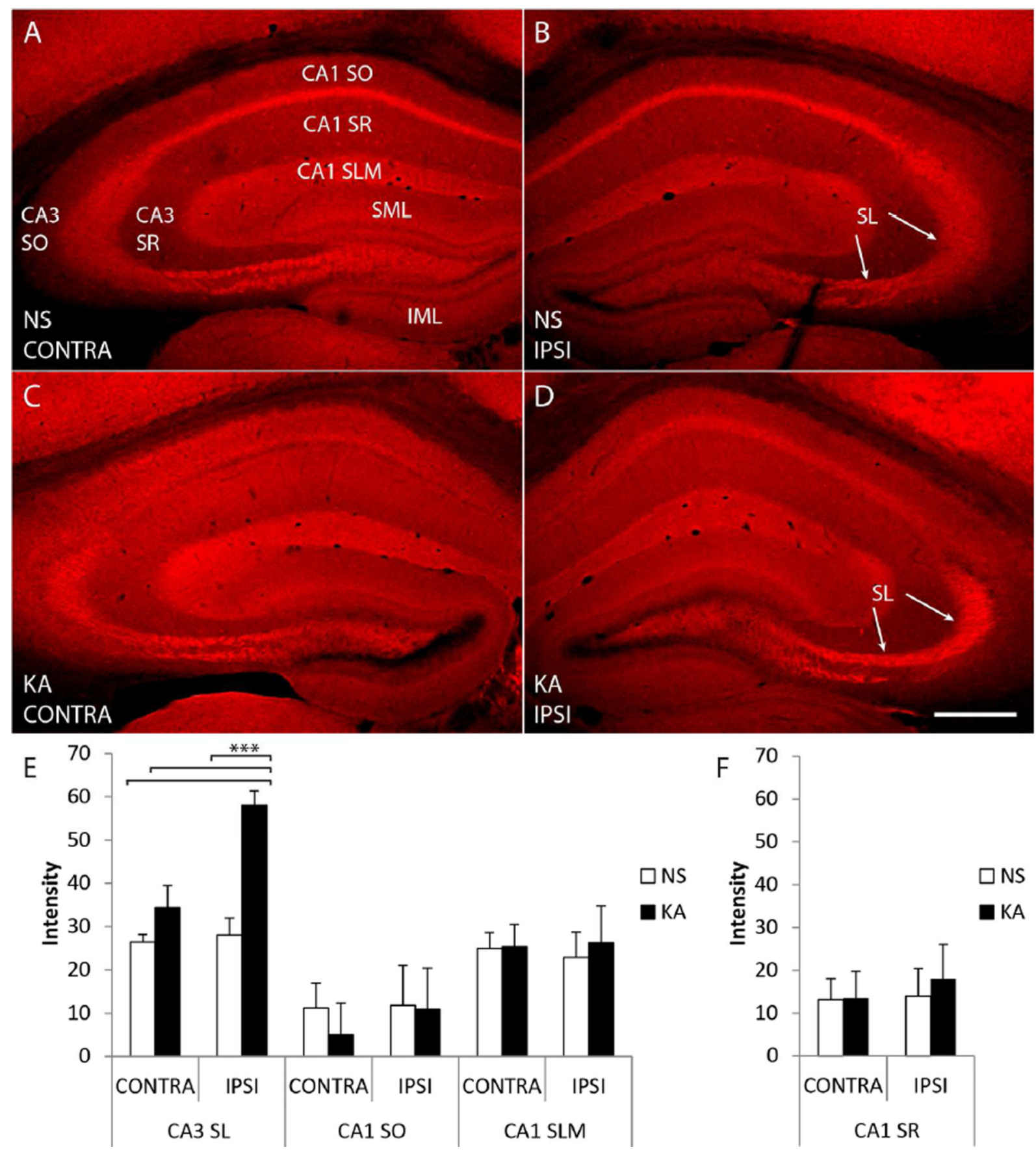

Figure 1. Immunoreactivity labeling phosphorylated tyrosine 816 (pY816) of TrkB is enhanced within stratum lucidum (SL) following kainic acid (KA) induced status epilepticus (SE), observed preferentially in the hippocampus ipsilateral to KA microinfusion A-D) Representative images of hippocampi stained with pY816 from animals infused with normal saline (A, B; NS, top) or given SE (C, D; KA, bottom) through microinfusion of KA into right amygdala (KA-SE). Hippocampi both ipsilateral (B, D; IPSI, right) and contralateral (A, C; CONTRA, left) to the side of infusion are shown. A noticeable increase in SL immunoreactivity can be discerned in the KA animal compared to NS on the side of infusion (B, D; arrows point to SL). Other regions within hippocampus that are referred to within the text are labeled for reference in (A): stratum radiatum of CA3 (CA3 SR), stratum 
oriens of CA3 (CA3 SO), stratum radiatum of CA1 (CA1 SR), stratum oriens of CA1 (CA1 SO), stratum lacunosum moleculare of CA1 (CA1 SLM), the suprapyramidal molecular layer of dentate gyrus (SML), and the infrapyramidal molecular layer of dentate gyrus (IML). Each image is a montage of two images taken at low magnification (100×). Scale bar $=300 \mu \mathrm{m}$. E) Low power $(100 \times)$ quantification of pY816 intensity in various regions from hippocampi both ipsilateral (IPSI) and contralateral (CONTRA) to microinfusion. A 2.1fold, highly significant increase ( $\mathrm{p}<0.001$, one-way ANOVA; $\mathrm{p}<0.001$, post-hoc

Bonferroni's test) was observed in CA3b SL of KA treated animals $(n=9)$ compared to NS $(n=9)$ on the side ipsilateral to infusion, whereas on the contralateral side the increase was only 1.3-fold ( $\mathrm{p}>0.05$, post-hoc Bonferroni's test). Analysis of CA1 SO and CA1 SLM did not demonstrate any significant differences in pY816 intensity between NS and KA treated mice on either side. F) Analysis of CA1 SR did not demonstrate differences in pY816 intensity between NS and KA treated animals either ipsilateral (IPSI) or contralateral (CONTRA) to infusion. All quantification is presented as mean intensity values \pm SEM; all data were analyzed by one-way ANOVA and post-hoc Bonferroni's test; ***p $<0.001$. 

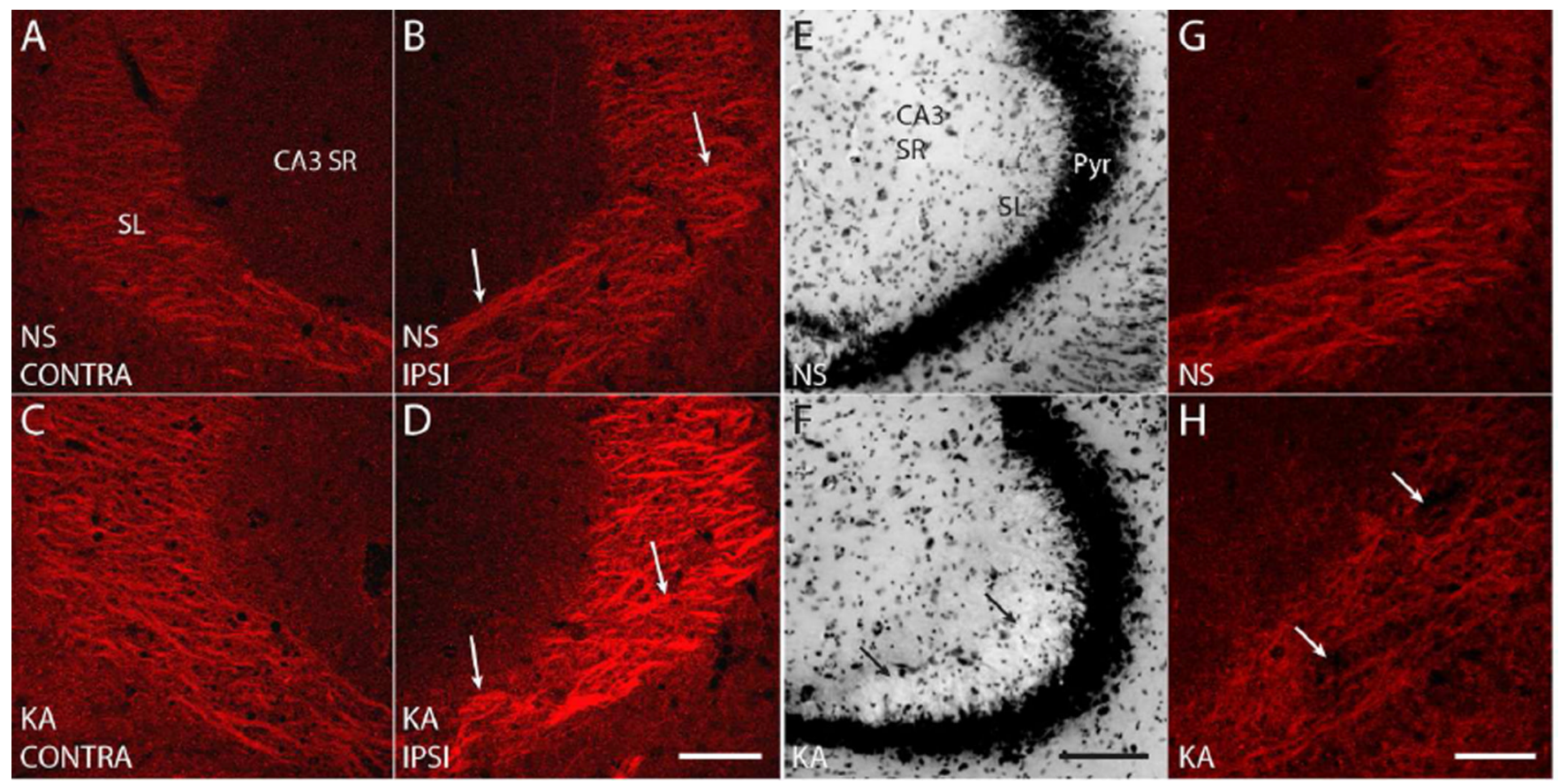

Figure 2. High magnification (630x) images reveal discrete patches of pY816 immunoreactivity within SL, enhanced preferentially on the side ipsilateral to KA microinfusion A-D) Representative high magnification (630x) images of SL from CA3b in NS (A, B; top) and KA (C, D; bottom) treated mice, both ipsilateral (B, D; IPSI, right) and contralateral (A, $\mathrm{C}$; CONTRA, left) to microinfusion. Arrows point to discrete patches of pY816 immunoreactivity that could be discerned within SL, and a noticeable increase in intensity of these immunoreactive areas can be seen in the KA treated animal ipsilateral to infusion compared to NS (B, D). Scale bar $=50 \mu \mathrm{m}$. E, F) Nissl stain of the CA3 region from a KA treated mouse (F) showing disruption of SL cytoarchitecture (arrows). The SL damage observed is representative of that found in two animals discarded from analysis due to this issue. Note the normal appearing SL in the NS treated littermate (E). Pyr is CA3 pyramidal cell layer. Scale bar $=100 \mu \mathrm{m} . \mathrm{G}, \mathrm{H})$ pY816 staining from the same hippocampi as in $(\mathrm{E}, \mathrm{F})$ demonstrates a relative paucity of stain in the KA treated animal (H; arrows) within SL compared to its NS infused littermate $(\mathrm{G})$. Scale bar $=50 \mu \mathrm{m}$. 

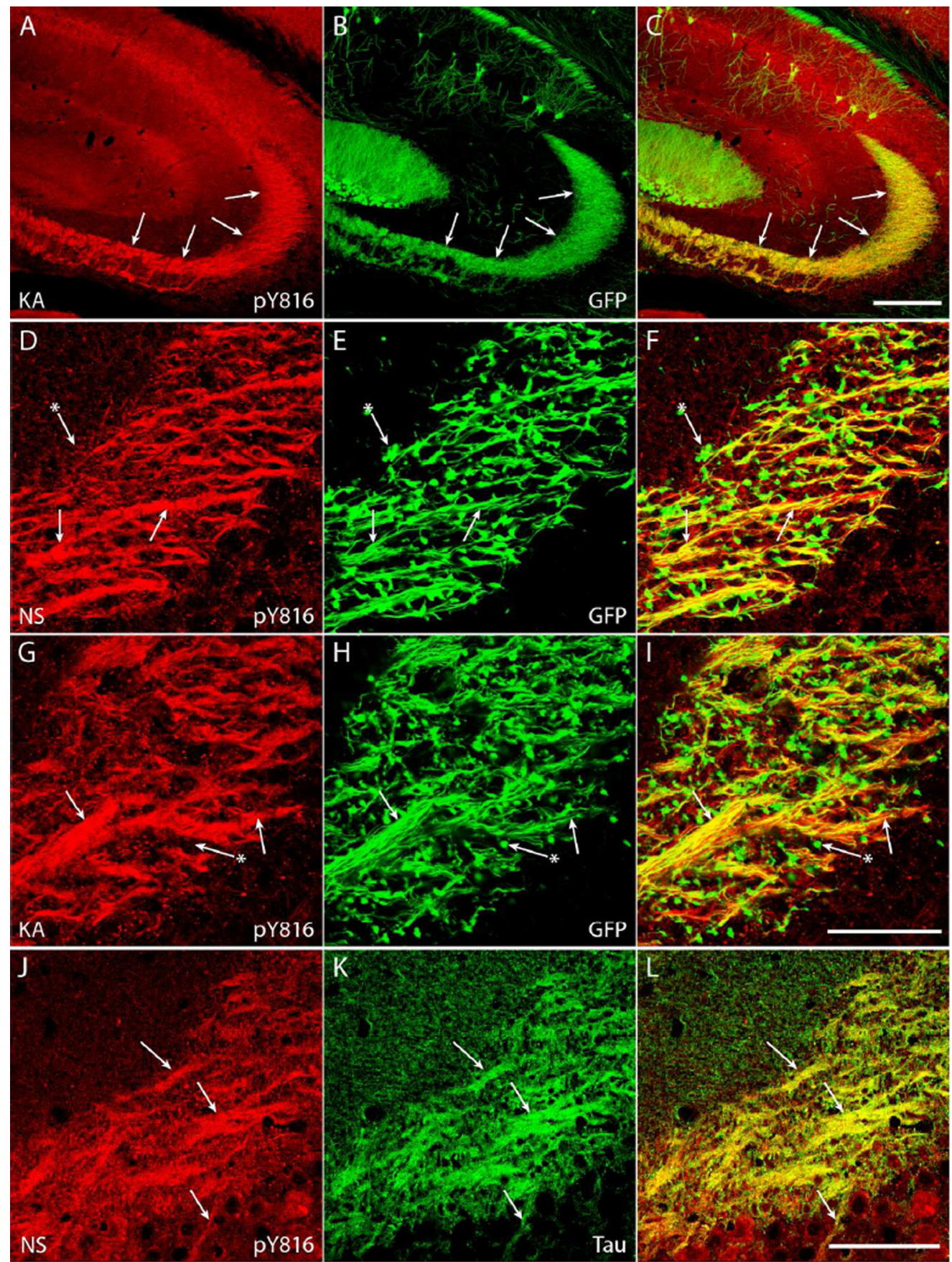

Figure 3. pY816 TrkB immunoreactivity colocalizes with axons of dentate granule cells (DGCs) in SL of hippocampus under both NS conditions and following KA-SE

A-C) Images of CA3 region of hippocampus from a KA treated animal demonstrates striking overlap of enhanced pY816 immunoreactivity (A; arrows) with GFP-labeled mossy fibers (B; arrows) that populate SL. Merged pY816 and GFP is shown in (C). Scale bar = $200 \mu \mathrm{m}$. D-I) Images from CA3b of SL of sections stained with pY816 (D, G) that also contain GFP (E, H) under conditions of NS infusion (D-F) and following KA-SE (G-I). A subset of mossy fiber axons of DGCs (E, H; arrows) are filled with GFP, and can be seen to colocalize with pY816 (D, G; arrows) under both NS and KA conditions. In contrast, most mossy fiber boutons (E, H; arrows with asterisks) do not contain prominent pY816 
immunoreactivity (D, G; arrows with asterisks) compared to axons. Note that the distribution of immunoreactivity does not change between NS and KA treated animals. Merged pY816 and GFP is shown in (F, I). Scale bar $=50 \mu \mathrm{m}$. J-L) Images from CA3b of SL from a control animal stained with pY816 (J) and tau (K), an axonal protein. Tau stained mossy fiber axon tracts (K; arrows) prominently colocalize with pY816 (J; arrows). Merged pY816 and Tau is shown in (L). Scale bar $=50 \mu \mathrm{m}$. 

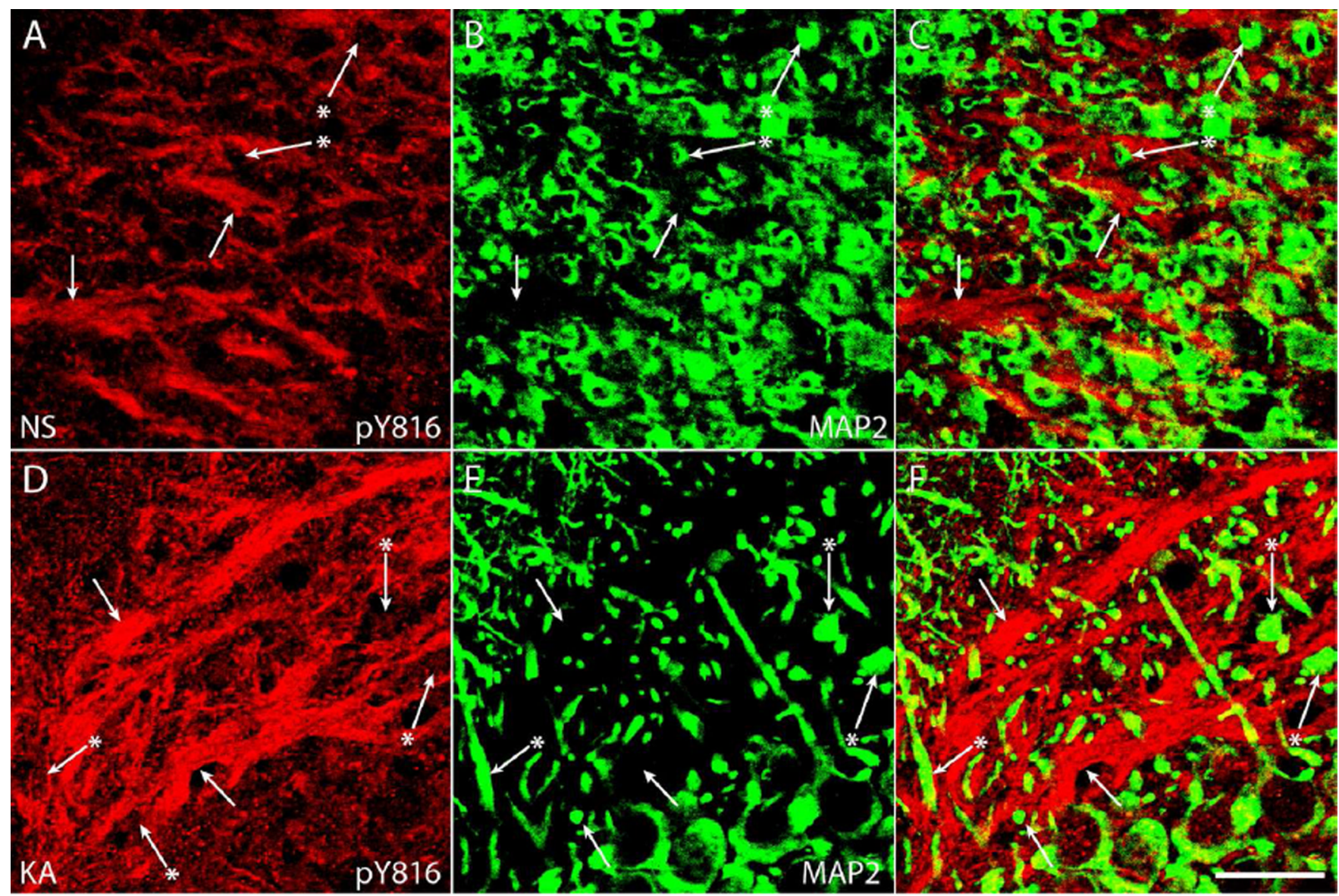

Figure 4. pY816 TrkB immunoreactivity does not prominently colocalize with MAP2 stained dendrites of CA3 pyramids under either NS conditions or following KA-SE

A-F) Images from CA3b of SL of pY816 stained sections (A, D) co-stained with MAP2 (B, E), a marker of dendrites, under conditions of NS infusion (A-C) and following KA-SE (DF). Linear patches of pY816 immunoreactivity (A, D; arrows), demonstrated to colocalize with mossy fiber axons (Fig. 3 and Supplementary Fig. 1), do not colocalize with MAP2 (B, E; arrows). Furthermore, MAP2 labeled dendrites of CA3 pyramidal cells (B, E; arrows with asterisks) do not contain prominent pY816 immunoreactivity (A, D; arrows with asterisks). Merged pY816 and MAP2 is shown in (C, F). No apparent differences are observed in the cellular distributions of pY816 immunoreactivity between NS and KA treated animals. Scale bar $=20 \mu \mathrm{m}$. 

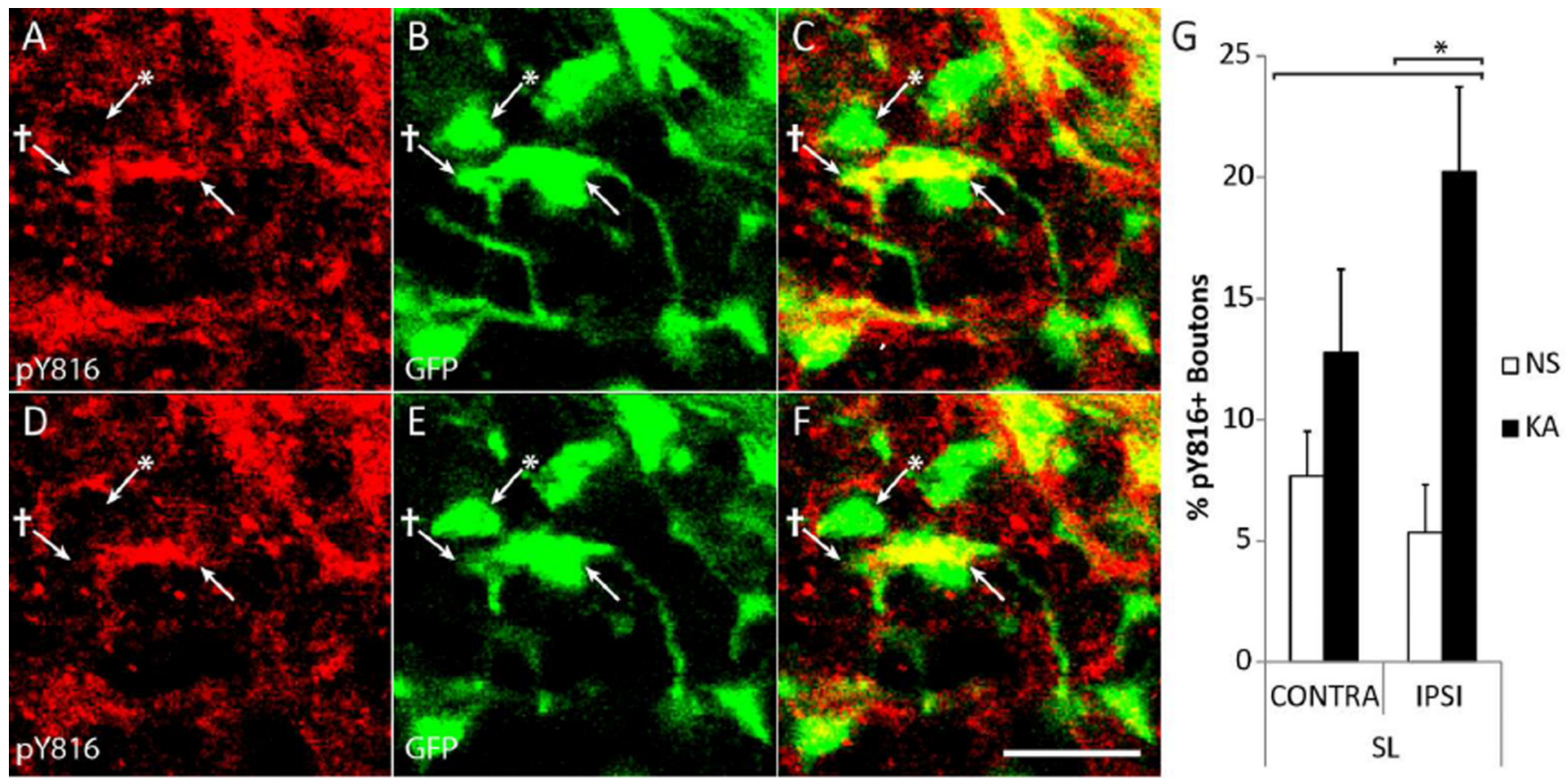

Figure 5. pY816 TrkB immunoreactivity is enhanced within synaptic mossy fiber boutons in SL following KA-SE, observed preferentially in the hippocampus ipsilateral to infusion A-F) Confocal micrographs of two $z$-sections (A-D, $z$-section one; D-F, $z$-section two) taken at a $1 \mu \mathrm{m}$ increment containing GFP+ mossy fiber boutons $(\mathrm{B}, \mathrm{E}$; arrow and arrow with asterisk) within SL ipsilateral to infusion in a KA treated animal. One bouton contains obvious pY816 immunoreactivity (A, D; arrow), whereas an adjacent bouton does not contain prominent pY816 (A, D; arrow with asterisk). Merged pY816 and GFP is shown in $(\mathrm{C}, \mathrm{F})$. A pY816 puncta within the bouton (A-C; arrow with dagger) disappears as the portion of the bouton containing it leaves the focal plane (D-F; arrow with dagger). Scale bar $=3.3 \mu \mathrm{m}$. G) Quantification of percentages of GFP+ boutons in SL found to contain pY816 immunoreactivity in Thy1 GFP-expressing mice under NS $(n=5)$ and KA $(n=5)$ treated conditions, both ipsilateral (IPSI) and contralateral (CONTRA) to the side of infusion. In boutons ipsilateral to KA infusion, a 3.8-fold ( $\mathrm{p}<0.01$, one-way ANOVA; $\mathrm{p}<0.05$, post-hoc Bonferroni's test) increase in the numbers of pY816+ boutons was observed compared to NS treated animals. On the contralateral side, there was only a 1.9fold ( $p>0.05)$ increase in the number of boutons containing immunoreactivity. A total of 901 boutons were analyzed under NS conditions, 934 under KA conditions. Quantification is presented as mean $\%$ of neuronal processes \pm SEM; all data analyzed by one-way ANOVA and post-hoc Bonferroni's test; $* \mathrm{p}<0.05$. 

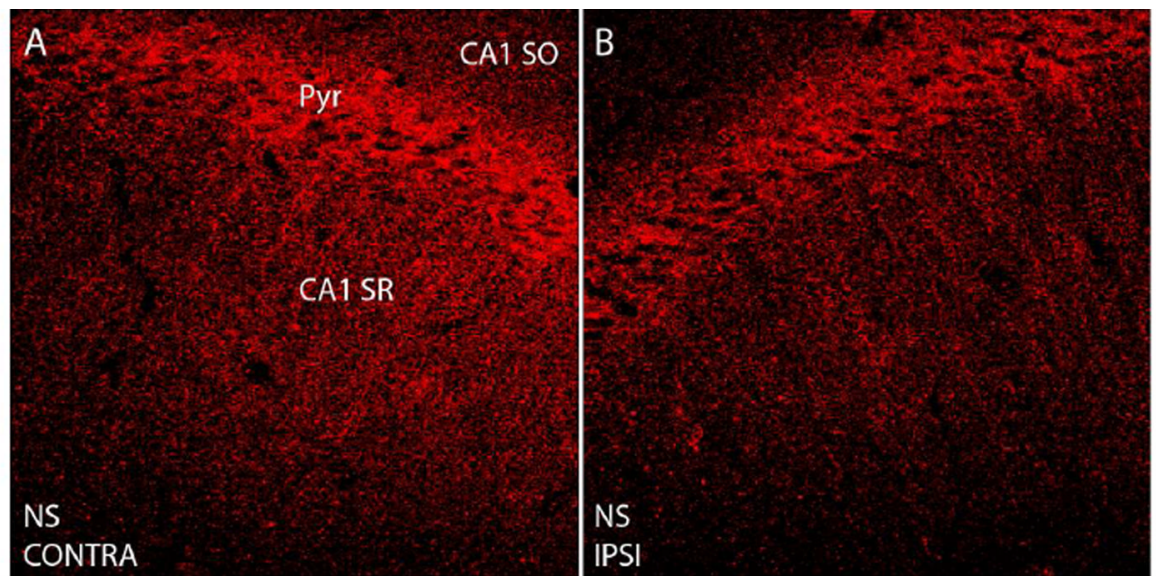

C

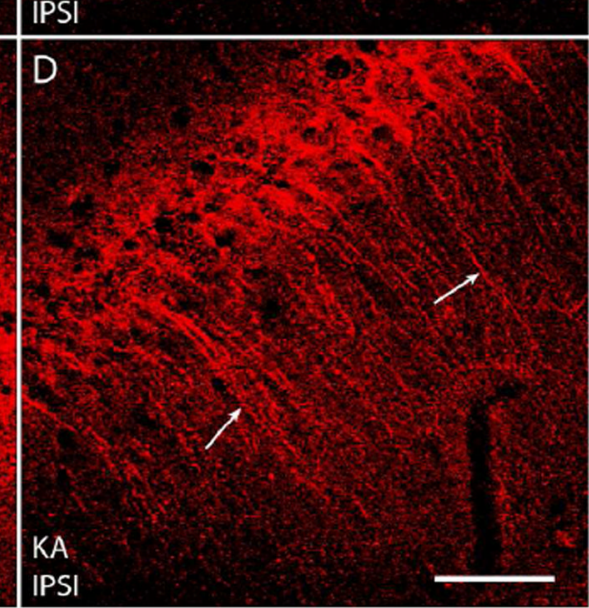

\section{CONTRA}

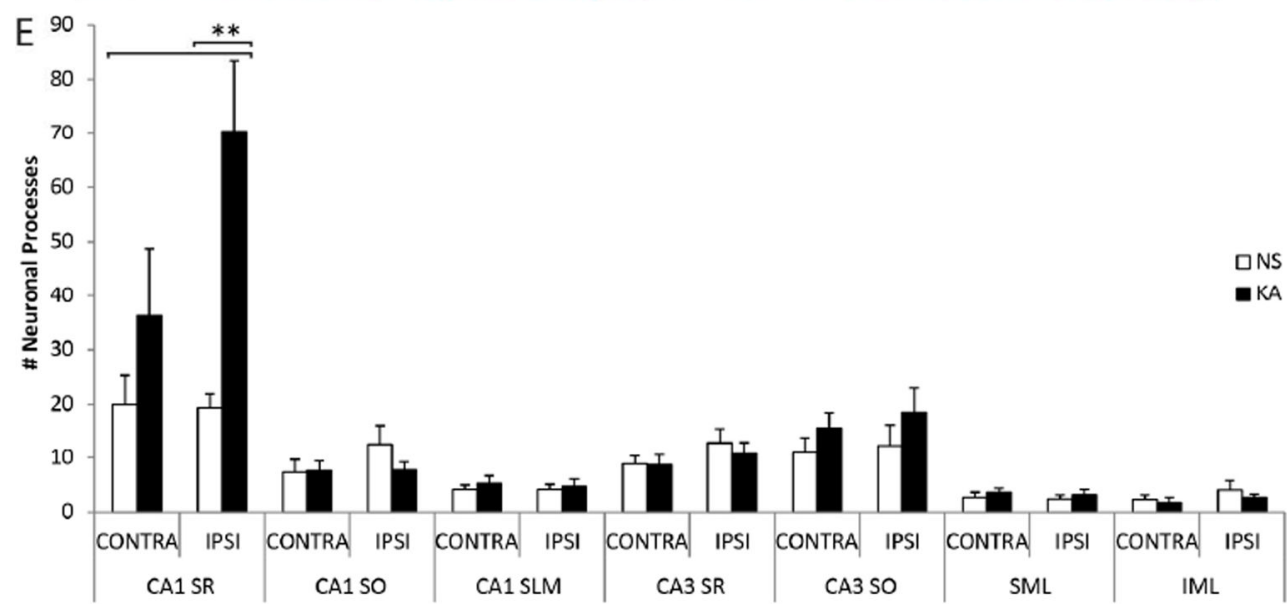

Figure 6. pY816 TrkB immunoreactivity is enhanced within apical dendrites of SR of CA1 following KA-SE, observed preferentially in the hippocampus ipsilateral to infusion A-D) Representative high power $(630 \times)$ images of CA1 SR (region marked top left) from sections stained with pY816. Animals were infused with either NS (A, B; top) or KA (C, D; bottom), and images taken from hippocampi both ipsilateral (B, D; IPSI, right) and contralateral (A, C; CONTRA, left) to the side of infusion. Apical dendrites of CA1 pyramidal cells labeled with pY816 immunoreactivity can be observed under SE conditions, most prominently on the side ipsilateral to KA infusion (D; arrows). Note that dendrites appear most immunoreactive in the region of SR more proximal to CA1 pyramidale (Pyr, marked top left). Scale bar $=50 \mu \mathrm{m}$. E) Quantification of total numbers of neuronal 
processes observed in two high magnification (630x) images taken from NS ( $\mathrm{n}=9)$ and KA $(n=9)$ treated animals, both ipsilateral and contralateral to the side of infusion. In CA1 SR ipsilateral to KA infusion, a 3.6-fold ( $\mathrm{p}<0.01$, one-way ANOVA; $\mathrm{p}<0.01$, post-hoc Bonferroni's test) increase in the numbers of discerned neuronal processes was observed compared to NS treated animals. On the contralateral side, there was only a 1.8-fold ( $>0.05$ ) increase in the number of pY816 apical dendrites stained. Quantification in the same fashion of CA1 SO, CA1 SLM, CA3 SR, CA3 SO, SML, and IML in hippocampi taken both ipsilateral and contralateral to infusion also demonstrated no significant differences in the numbers of discerned neuronal processes between NS and KA conditions on either side (CA1 SO p=0.342, CA1 SLM p=0.885, CA3 SR p=0.462, CA3 SO p=0.449, SML $\mathrm{p}=0.758$, IML $\mathrm{p}=0.557$ by one-way ANOVA). Quantification is presented as mean number of neuronal processes \pm SEM; all data analyzed by one-way ANOVA and post-hoc Bonferroni's test; ${ }^{* *} \mathrm{p}<0.01$. 


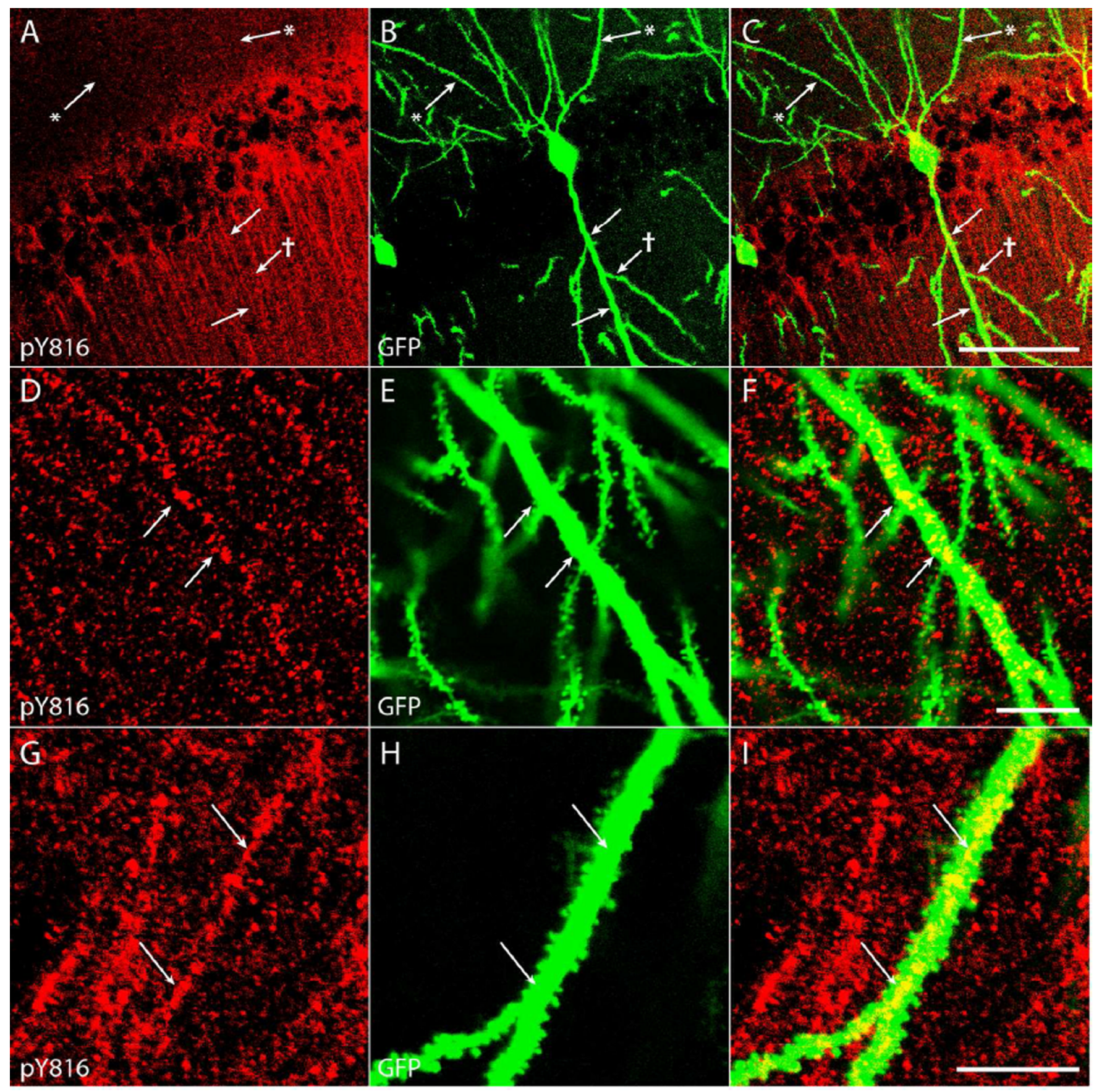

Figure 7. pY816 TrkB immunoreactivity is intracellular and punctate within the dendritic shaft of proximal apical dendrites of CA1 pyramidal cells

A-C) The primary apical dendrite of a GFP+ CA1 pyramidal neuron (B; arrows) contains clear pY816 immunoreactivity (A; arrows) within its aspinous proximal shaft, whereas a secondary dendritic branch (B; arrow with dagger) does not contain prominent immunoreactivity within its shaft (A; arrow with dagger). Basal dendritic processes (B; arrows with asterisks) clearly do not contain pY816 immunoreactivity (A; arrows with asterisks). Merged pY816 and GFP is shown in (C). Image is a maximum projection (displaying the region of highest intensity) of multiple confocal scans taken at $0.4 \mu \mathrm{m}$ increments in the $z$-plane. Scale bar $=50 \mu \mathrm{m}$. D-F) Close-up of a proximal, aspinous portion 
of a GFP+ apical dendritic process (E; arrows) with intracellular, punctate pY816 immunoreactivity (D; arrows) within the shaft. Merged pY816 and GFP is shown in (F). Scale bar $=10 \mu \mathrm{m}$. G-I) A spiny portion of a GFP+ apical dendrite (H; arrows) also displaying intracellular, punctate pY816 immunoreactivity (G; arrows) within the shaft. Merged pY816 and GFP is shown in (I). Scale bar $=10 \mu \mathrm{m}$. 

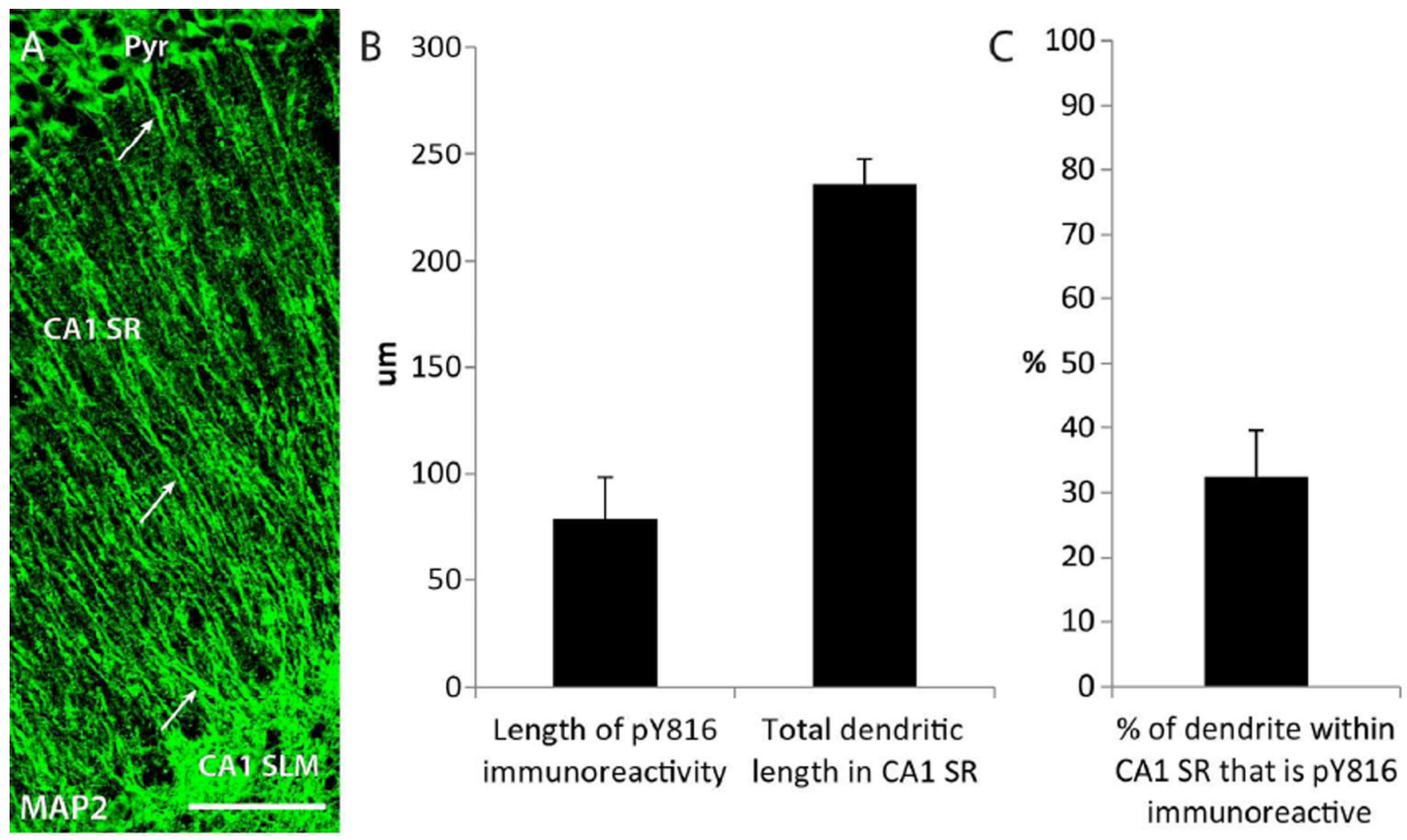

Figure 8. pY816 TrkB immunoreactivity is enriched preferentially within the portion of the apical dendritic shaft of CA1 pyramidal cells more proximal to soma

A) Image of the entire longitudinal span of CA1 SR, from pyramidale (Pyr) to CA1 SLM, stained with MAP2. Prominent dendritic shaft labeling by MAP2 can be seen within the entire vertical span of CA1 SR (arrows), showing that apical dendrites remain within the focal plane throughout. Scale bar $=50 \mu \mathrm{m}$. B) Quantification of the total distance that pY816 immunoreactivity in GFP+ apical dendritic shafts was found to extend distally into CA1 SR in a KA treated animal, measured from soma ( $n=6$ dendritic shafts). Only GFP+ dendritic shafts that were also found to be pY816+ were used in this analysis. The entire lengths of these GFP+ dendrites were imaged until their intersection with SLM, and total dendritic length from soma to SLM was also quantified. pY816 immunoreactivity was found to extend an average of $78.7 \pm 19.4 \mu \mathrm{m}$ into the shaft, whereas average dendritic length was found to be $235.8 \pm 11.7 \mu \mathrm{m}$. C) Quantification of the percent of total dendritic length that pY816 immunoreactivity was found to occupy $(n=6)$, using measurements made from the same dendritic shafts as in (B). Immunoreactivity was found, on average, within $38 \pm 7 \%$ of the most proximal portion of pY816+ apical dendritic shafts within CA1 SR. Error bars represent SEM. 

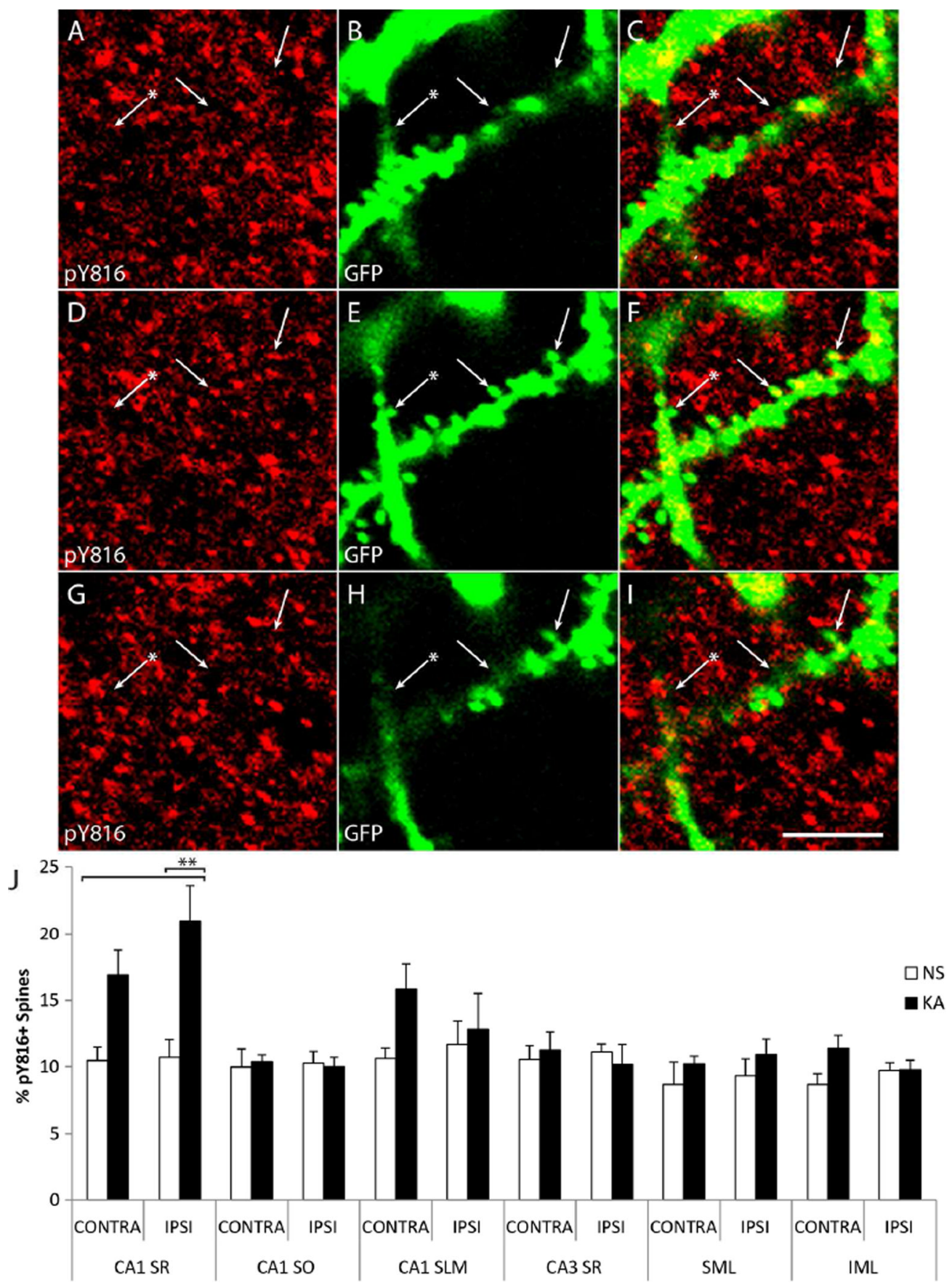

Figure 9. pY816 TrkB immunoreactivity is enhanced within dendritic spines in CA1 SR following KA-SE, observed preferentially in the hippocampus ipsilateral to infusion

A-I) Confocal micrographs from CA1 SR from a Thy1-GFP mouse treated with KA. Three $Z$-sections are shown taken at $750 \mathrm{~nm}$ increments above (A-C; top), within (D-F; middle), and below (G-I; bottom) two GFP+ spines (E; arrows) of an apical dendrite that contain small pY816 puncta (D; arrows). Other spines (E; arrow with asterisk) do not appear to contain pY816 (D; arrow with asterisk). Note colocalization of pY816 with spines in the $z-$ plane (observe panels from top to bottom and note arrows), such that these pY816 puncta are observable within the spine but not above or below it. Merged pY816 and GFP images are shown in $(\mathrm{C}, \mathrm{F}, \mathrm{I})$. Scale bar $=2.5 \mu \mathrm{m}$. J) Quantification of percentages of GFP+ spines 
found to contain pY816 immunoreactivity in Thy 1 GFP-expressing mice in CA1 SR, CA1 SO, CA1 SLM, CA3 SR, the outer twothirds of SML, and the outer two-thirds of IML. This was quantified under both NS $(n=5)$ and KA $(n=5)$ conditions, both ipsilateral (IPSI) and contralateral (CONTRA) to the side of infusion. In spines of CA1 SR ipsilateral to KA infusion, a 2.0-fold increase in the numbers of pY816+ spines was observed compared to NS treated animals ( $\mathrm{p}<0.01$, one-way ANOVA; $\mathrm{p}<0.01$, post-hoc Bonferroni's test). The contralateral side demonstrated a more modest, 1.6-fold increase which was not significant. Data is from 994 spines analyzed under NS conditions, 1020 spines analyzed under KA conditions. No significant differences in the numbers of pY816+ spines were found in any of the other regions analyzed (CA1 SO p=0.993, 2097 spines; CA1 SLM p=0.272, 2428 spines; CA3 SR p=0.899, 2263 spines; SML $p=0.604,1940$ spines; IML $p=0.128,1958$ spines, oneway ANOVA). Quantification is presented as mean $\%$ of neuronal processes \pm SEM; all data analyzed by one-way ANOVA and post-hoc Bonferroni's test; **p $<0.01$. 
Table 1

Primary antibodies employed in this study.

\begin{tabular}{|l|l|l|l|}
\hline Target & Immunogen & Source & Working Dilution \\
\hline $\begin{array}{l}\text { Phosphorylated } \\
\text { tyrosine residue 816 (pY816) of } \\
\text { TrkB Receptor }\end{array}$ & $\begin{array}{l}\text { LQNLAKASPVpYLDI, } \\
\text { corresponding to amino } \\
\text { acids 806-819 of mouse } \\
\text { TrkB. }\end{array}$ & $\begin{array}{l}\text { McNamara Laboratory; } \\
\text { Rabbit Polyclonal. }\end{array}$ & $1: 2000$ \\
\hline $\begin{array}{l}\text { Green Fluorescent Protein } \\
\text { (GFP) }\end{array}$ & GFP-BSA & $\begin{array}{l}\text { Millipore; Mouse } \\
\text { Monoclonal; MAB3580. }\end{array}$ & $1: 1000$ \\
\hline MAP2 & $\begin{array}{l}\text { Rat brain microtubule- } \\
\text { associated proteins (MAPs). }\end{array}$ & $\begin{array}{l}\text { Sigma; Mouse Monoclonal; } \\
\text { M4403. }\end{array}$ & $1: 500$ \\
\hline Tau-1 & $\begin{array}{l}\text { Purified denatured bovine } \\
\text { microtubule associated } \\
\text { proteins. }\end{array}$ & $\begin{array}{l}\text { Millipore; Mouse } \\
\text { Monoclonal; MAB3420. }\end{array}$ & $1: 1000$ \\
\hline
\end{tabular}


Table 2

Secondary antibodies employed in this study.

\begin{tabular}{|l|l|l|}
\hline Secondary Antibody & Source & Working Dilution \\
\hline $\begin{array}{l}\text { Alexa Fluor 555 Goat Anti-Rabbit } \\
\text { IgG (H+L), highly cross-adsorbed }\end{array}$ & Invitrogen; A-21429 & $1: 1000$ \\
\hline $\begin{array}{l}\text { Alexa Fluor 488 Goat Anti-Mouse } \\
\text { IgG (H+L), highly cross-adsorbed }\end{array}$ & Invitrogen; A-11029 & $1: 500$ \\
\hline $\begin{array}{l}\text { Alexa Fluor 633 Goat Anti-Mouse } \\
\text { IgG (H+L), highly cross-adsorbed }\end{array}$ & Invitrogen; A-21052 & $1: 500$ \\
\hline
\end{tabular}

